Check for updates

Cite this: Mater. Adv., 2021,

2, 1715

Received 23rd November 2020,

Accepted 24th January 2021

DOI: 10.1039/d0ma00917b

rsc.li/materials-advances

\title{
Silicon oxycarbonitride ceramic containing nickel nanoparticles: from design to catalytic application $\dagger$
}

\author{
Jun Wang, ${ }^{a}$ Albert Gili, ${ }^{\text {ab }}$ Matthias Grünbacher, ${ }^{c}$ Sebastian Praetz, ${ }^{d}$ Jan Dirk Epping, ${ }^{e}$ \\ Oliver Görke, ${ }^{a}$ Götz Schuck, ${ }^{\dagger}$ Simon Penner, (D) Christopher Schlesiger, (DD ${ }^{d}$ \\ Reinhard Schomäcker, ${ }^{b}$ Aleksander Gurlo ${ }^{a}$ and Maged F. Bekheet (D) *a
}

\begin{abstract}
Nickel-containing silicon oxycarbonitride ceramic nanocomposites are synthesized from hydrous nickel acetate and poly(vinyl)silazane (Durazane 1800) or perhydropolysilazane NN120-20 (A) (PHPS). A room temperature chemical reaction results in Ni-containing polysilazane precursors which are transformed into ceramic nanocomposites with nickel nanoparticles $(2-4 \mathrm{~nm})$ upon pyrolysis at elevated temperatures (700-1100 ${ }^{\circ} \mathrm{C}$ ) under an argon atmosphere. The ceramic nanocomposites derived from the Durazane 1800 - Ni precursor by the thermolysis process at 700 and $900{ }^{\circ} \mathrm{C}$ manifest a microporous structure with a BET specific surface area of $\sim 361$ and $\sim 232 \mathrm{~m}^{2} \mathrm{~g}^{-1}$, respectively. In contrast, all pyrolyzed samples derived from the PHPS-Ni precursor exhibit a nonporous structure. The Ni/SiOCN ceramic nanocomposites - tested in a plug-flow fixed-bed reactor - display significant catalytic activity in dry methane reforming to syngas. The highest $\mathrm{CH}_{4}$ reaction rate of $0.18 \mathrm{~mol} \mathrm{~min}{ }^{-1} \mathrm{gNi}^{-1}$ is observed at $800{ }^{\circ} \mathrm{C}$ for the sample derived from the PHPS-Ni precursor by pyrolysis at $900{ }^{\circ} \mathrm{C}$. All these make the materials developed in this work, i.e. nickel nanoparticles in situ formed in the SiOCN ceramic matrix, as promising candidates for heterogeneous catalysis.
\end{abstract}

\section{Introduction}

Metal nanoparticles can be used for a wide range of applications varying from spintronics to electrocatalysis and heterogeneous catalysis. ${ }^{1-5}$ However, the low chemical stability and sintering of metal nanoparticle catalysts under operating conditions limit their practical applications. These problems have been solved by embedding these metal nanoparticles into ceramic supports such as silica, ${ }^{6}$ alumina, ${ }^{7}$ zirconia, ${ }^{8}$ and other

\footnotetext{
${ }^{a}$ Fachgebiet Keramische Werkstoffe/Chair of Advanced Ceramic Materials, Institut für Werkstoffwissenschaften und-technologien, Technische Universität Berlin, Hardenbergstraße 40, 10623 Berlin, Germany. E-mail:maged.bekheet@ceramics.tu-berlin.de

${ }^{b}$ Institut für Chemie, Technische Universität Berlin, Sekretariat TC 8, Straße des 17. Juni 124, 10623 Berlin, Germany

${ }^{c}$ Institute of Physical Chemistry, University of Innsbruck, Innrain 52c, A-6020 Innsbruck, Austria

${ }^{d}$ Institute of Optics and Atomic Physics, Technische Universität Berlin, Hardenbergstraße 36, 10623 Berlin, Germany

${ }^{e}$ Metalorganics and Inorganic Materials, Institut für Chemie, Technische Universität Berlin, Straße des 17. Juni 135, 10623 Berlin, Germany

${ }^{f}$ Helmholtz-Zentrum Berlin für Materialien und Energie, Hahn-Meitner-Platz 1, 14109 Berlin, Germany

$\dagger$ Electronic supplementary information (ESI) available. See DOI: 10.1039/ d0ma00917b
}

metal oxides. ${ }^{9-14}$ Although these supports are commercially available, they display several drawbacks, such as poor thermal conductivity and chemical reactivity at high temperatures. Silicon-based polymer-derived ceramics (PDCs), which are well known for their excellent thermomechanical properties, high thermal stability, and high resistance towards corrosion and oxidation under extreme environmental conditions,${ }^{15-17}$ might be a promising candidate for replacing these commercial supports. Micro-mesoporous PDCs with high surface areas have been reported as promising catalytic supports. ${ }^{18-20}$ For instance, metalcontaining (e.g. Co and Ni) SiOC nanocomposites with hierarchical porosity, derived from polysiloxane polymers, show high catalytic activity for $\mathrm{CO}_{2}$ methanation and Fischer-Tropsch synthesis. ${ }^{18,20-24}$ Similarly, some transition metal-containing (e.g. $\mathrm{Cu}, \mathrm{Ru}, \mathrm{Pd}$, and Ir) SiCN nanocomposites have been reported as heterogeneous catalysts for liquid-phase oxidation, ${ }^{25}$ hydrogeneration, ${ }^{26,27}$ and sustainable synthesis. ${ }^{28}$

Silicon-based PDCs have been synthesized in single- and multi-phase as well as nanocomposite structures by thermal pyrolysis of organosilicon polymer precursors denoted as preceramic polymers. ${ }^{29-31}$ Metal-containing PDC nanocomposites have been commonly prepared by direct mixing of preceramic polymers with $\mathrm{metal} / \mathrm{metal}$ oxide powders, followed by thermolysis under a controlled atmosphere. ${ }^{32-35}$ However, this approach 
might lead to pore blocking effects, heterogeneous distributions, and agglomeration of the metal nanoparticles in the ceramic supports. Therefore, the in situ formation of metal nanoparticles during the synthesis of the microporous/mesoporous PDC matrix has been alternatively applied. This approach can be achieved by the thermolysis of (i) commercially available metallopolymers or (ii) organosilicon polymers modified by metallorganic compounds. Metallopolymers are usually pyrolyzed at relatively low temperatures. For instance, uniform metallic $\alpha$-Fe nanoparticles with an average size of $4 \mathrm{~nm}$ have been in situ formed in the SiC matrix during the thermolysis of poly(ferrocenylsilanes) (PFSs) at $700{ }^{\circ} \mathrm{C}$ under a nitrogen atmosphere. ${ }^{36}$ However, this synthesis approach is greatly restricted by the variety of available metallopolymers. In contrast, the chemical modification of preceramic polymers with metallorganic compounds has been widely used because most of the organosilicon polymers contain functional groups, such as $\mathrm{Si}-\mathrm{H}, \mathrm{N}-\mathrm{H}$, and $-\mathrm{CH}=\mathrm{CH}_{2}$, which can easily react with metallorganic compounds to obtain metal-modified polymer precursors. Metal carbonyls, ${ }^{37}$ metal alkoxides, ${ }^{38}$ metal acetylacetonates, ${ }^{39}$ and bis(cyclopentadienyl) metal dichlorides $\left(\mathrm{Cp}_{2} \mathrm{MCl}_{2}\right)^{40}$ are a few examples of metallorganic compounds that can react with preceramic polymers. Nevertheless, some metallorganic compounds are extremely toxic, and harsh reaction conditions are usually required. Recently, Motz et al. have developed a molecular approach to incorporate transition metals (e.g. Fe, $\mathrm{Ni}, \mathrm{Cu}$, and $\mathrm{Pt}$ ) into the PDC matrix by the chemical modification of polysilazane HTT1800 with aminopyridinato metal complexes. ${ }^{25,41-43}$ In situ formation of nickel nanoparticles during the reaction of the polysilazane HTT1800 polymer with trans-[bis(2-aminoethanol- $N, O$ )diacetato-nickel(II)] in an ice bath under an argon atmosphere appeared to be a quite complex process due to the complicated and time-consuming synthesis of the nickel(II)-containing complex. ${ }^{44,45}$

In our previous work, we designed and successfully synthesized several $\mathrm{M} / \mathrm{SiOCN}$ nanocomposites $(\mathrm{M}=\mathrm{Mn}, \mathrm{Fe}, \mathrm{Co}, \mathrm{Cu}, \mathrm{Zn}$, and Ag) by chemical reaction of poly(vinyl)silazane (Durazane 1800) with metal acetates followed by pyrolysis of as-derived precursors. ${ }^{46}$ Most of the metal nanoparticles were in situ formed in the synthesized precursors during the reaction at room temperature. Transition metals (Fe and $\mathrm{Co}$ ) catalyzed the cross-linking of polymer precursors, which in turn increased the final ceramic yield. Compared with previous approaches, our synthesis method appeared to be advantageous, owing to the very simple reaction conditions (in an ice bath under an argon atmosphere), the use of rather inexpensive poly(vinyl)silazane (Durazane 1800), and easily accessible commercial metal acetate materials. Accordingly, in the present work, we extend our approach to synthesize Ni-containing precursors by reacting nickel(II) acetate tetrahydrate with either poly(vinyl)silazane (Durazane 1800) or carbon-free perhydropolysilazane NN120-20 (A) (PHPS). These two polymers are chosen for the present study because they possess different molecular structures, which allows us to study the influence of the hydrocarbon side groups, such as methyl and vinyl groups of Durazane 1800 on the chemical compositions, microstructures and catalytic properties of the resulting ceramic nanocomposites. We mainly focus on the clarification of the reaction mechanism between nickel(II) acetate tetrahydrate and polysilazanes through comprehensive characterizationof the synthesized Ni-containing precursors. In addition, the polymer-to-ceramic transformation process, phase compositions, and porosity development in the pyrolyzed ceramic nanocomposites are investigated. The catalytic performance of obtained Ni/SiOCN ceramic nanocomposites (porous SiOCN ceramic matrix-supported very fine $\mathrm{Ni}$ nanoparticles) towards dry reforming of methane (DRM) with carbon dioxide is evaluated for the first time. As compared with previous studies on Ni-based catalysts, ${ }^{11,12,47-53}$ the obtained Ni/SiOCN catalysts show remarkable catalytic activity towards the DRM process even though the catalyst configuration was not optimized for this particular reaction. Thus, the in situ formation of nickel nanoparticles in the PDC matrix can be a promising approach to prepare heterogeneous catalysts for the DRM process.

\section{Experimental methods}

\section{Materials}

Nickel(II) acetate tetrahydrate $\left(\mathrm{Ni}(\mathrm{Ac})_{2} \cdot 4 \mathrm{H}_{2} \mathrm{O}, \geq 99.9\right)$ and anhydrous tetrahydrofuran (THF, $\geq 99.99 \%$ ) were obtained from SigmaAldrich. Poly(vinyl)silazane Durazane 1800 and NN120-20 (A) that is a $20 \mathrm{wt} \%$ solution of perhydropolysilazane (PHPS) in di- $n$-butyl ether were purchased from durXtreme $\mathrm{GmbH}$, Germany. Argon gas used during both the reaction and pyrolysis steps was used as received (>99.999\%).

\section{Synthesis of Ni-containing polysilazane precursors}

All synthesis reactions were carried out according to the following procedures reported recently: ${ }^{46} 4 \mathrm{~g}$ Durazane 1800 or $20 \mathrm{~g}$ NN120-20 (A) (i.e. $4 \mathrm{~g}$ PHPS) was first dissolved in $50 \mathrm{~mL}$ anhydrous THF and then added into a dropping funnel. Similarly, $1.6 \mathrm{~g} \mathrm{Ni}(\mathrm{Ac})_{2}$. $4 \mathrm{H}_{2} \mathrm{O}$ was dispersed in $50 \mathrm{~mL}$ anhydrous THF in another flask. The flask and dropping funnel were then assembled in a glovebox without allowing both reactants to be mixed. The reaction assembly was immediately removed from the glovebox. The flask containing nickel acetate tetrahydrate solution was connected to Schlenk-lines and submerged in an ice bath $\left(-6{ }^{\circ} \mathrm{C}\right)$. Polymer and nickel acetate tetrahydrate were then mixed in the flask by opening the valve of the dropping funnel under slow argon flow. The synthesis process continued under slow argon flow and was stirred for $24 \mathrm{~h}$ until the end of gas liberation. Finally, the THF solvent was removed under vacuum for at least $5 \mathrm{~h}$, and the synthesized Ni-containing precursors were collected in the glovebox. The synthesized Ni-containing precursors derived from Durazane 1800 and PHPS were denoted as Du1800-Ni and PHPS-Ni precursors, respectively.

\section{Synthesis of Ni/SiOCN ceramic nanocomposites}

Ceramic nanocomposites were obtained by the thermolysis of the synthesized Du1800-Ni and PHPS-Ni precursors in a tube furnace using a quartz Schlenk tube under flowing argon (approximately $40 \mathrm{~mL} \mathrm{~min}^{-1}$ ) at three different pyrolysis temperatures $\left(700,900\right.$, and $1100{ }^{\circ} \mathrm{C}$ ). In a typical pyrolysis route, the obtained Ni-containing precursors were heated from room 
temperature to $250{ }^{\circ} \mathrm{C}$ with a rate of $50{ }^{\circ} \mathrm{C} \mathrm{h}^{-1}$, held for $2 \mathrm{~h}$ at $250{ }^{\circ} \mathrm{C}$, heated from $250{ }^{\circ} \mathrm{C}$ to a final pyrolysis temperature $(700$, 900 or $1100{ }^{\circ} \mathrm{C}$ ) with a rate of $50{ }^{\circ} \mathrm{C} \mathrm{h}^{-1}$ and held for $3 \mathrm{~h}$ at this temperature and finally cooled to room temperature with a rate of $180{ }^{\circ} \mathrm{C} \mathrm{h}^{-1}$. The ceramic nanocomposites obtained by pyrolyzing the Du1800-Ni precursor at 700, 900, and $1100{ }^{\circ} \mathrm{C}$ are labeled as 700Ar-Du1800-Ni, 900Ar-Du1800-Ni, and 1100Ar-Du1800-Ni, respectively, while, the samples obtained at the same temperatures but from the PHPS-Ni precursor are denoted as 700ArPHPS-Ni, 900Ar-PHPS-Ni and 1100Ar-PHPS-Ni, respectively. The schematic of the synthesis of Ni/SiOCN ceramic nanocomposites is shown in Fig. $\mathrm{S} 1$ (ESI $\dagger$ ).

\section{Catalytic tests}

Catalytic tests were performed using a plug-flow fixed-bed reactor. For a given test, $25 \mathrm{mg}$ of catalyst was diluted using quartz (washed and calcined, 200-800 $\mu \mathrm{m}$ particle size, from Merck) to a total volume of $0.5 \mathrm{~cm}^{3}$ and implemented inside a quartz tubular reactor (4 $\mathrm{mm}$ inner diameter, $400 \mathrm{~mm}$ of length). The reactor was mounted inside a Reetz $\mathrm{GmbH}$ oven, and a k-type thermocouple placed at the packed-bed height next to the reactor wall allowed for temperature control. Gas flow was controlled with different mass flow controllers (MFCs) by Bronkhorst High-Tech B.V. $\mathrm{CH}_{4}$ (purity of 99.95\%), $\mathrm{CO}_{2}$ (purity of $99.995 \%$ ), $\mathrm{H}_{2}$ (purity of $99.999 \%$ ), and $\mathrm{N}_{2}(99.999 \%$ ) gases were purchased from Air Liquide. All the catalytic tests were performed at reactant ratios of $\mathrm{CH}_{4}: \mathrm{CO}_{2}: \mathrm{N}_{2}=1: 1: 3$ and $\mathrm{GHSV}=120000 \mathrm{~N} \mathrm{~mL} \mathrm{~h}^{-1} \mathrm{~g}_{\text {cat }}{ }^{-1}$. Heating to $500{ }^{\circ} \mathrm{C}$ and cooling after catalysis were performed under the $\mathrm{N}_{2}$ flow of $30 \mathrm{~N} \mathrm{~mL} \mathrm{~min}^{-1}$ and $20{ }^{\circ} \mathrm{C} \min ^{-1}$. Before testing, the catalysts were in situ reduced at $500{ }^{\circ} \mathrm{C}$ using a $10 \% \mathrm{H}_{2}: \mathrm{N}_{2}(\mathrm{v} / \mathrm{v})$ of $30 \mathrm{~N} \mathrm{~mL} \mathrm{m^{-1 }}$ for 1 hour. Gas characterization was performed using a $7890 \mathrm{~A}$ gas chromatograph (GC) from Agilent Technologies equipped with FID and TCD detectors. Prior to testing, the GC was calibrated using calibration gas bottles purchased from Deuste Gas Solutions. To ensure reproducibility, the back pressure of the GC was controlled using a Swagelok K-series pressure regulator. A carbon balance was performed to all data points and was always above $95 \%$.

\section{Characterization methods}

Attenuated total reflectance Fourier transform infrared spectroscopy (ATR-FTIR) measurements of the synthesized Nicontaining precursors and pyrolyzed samples were measured from $550 \mathrm{~cm}^{-1}$ to $4000 \mathrm{~cm}^{-1}$ in the glovebox using Nicolet is5 (Thermo Fisher Scientific, USA) and Specac Golden Gate (Waltham, MA, USA) with a diamond plate. X-ray photoelectron spectroscopy (XPS) was performed on an ESCALAB 250Xi (Thermo Fisher Scientific, USA). The size of the X-ray spot on the sample was $100 \mu \mathrm{m}$. The samples for X-ray photoelectron measurement were prepared by sprinkling a small amount of sample powders onto the surface of sticky carbon conductive tape on the sample holder in the glovebox. All XPS spectra were calibrated using the C 1 s core line with a binding energy of $284.8 \mathrm{eV}$. The released gases during the synthesis were determined using a gas chromatography system (Agilent 7820A, USA) equipped with a thermal conductivity detector. Synchrotron X-ray diffraction (XRD) measurements were carried out at the beamline 12.2.2 of the Advanced Light Source (Lawrence National Berkeley Laboratory, California, USA) using monochromatic synchrotron radiation with $\lambda=0.495 \AA$ (25 keV/30 $\mu \mathrm{m}$ spot size) in the angle-dispersive transmission mode using an RDI flat panel detector with the dark image and strain correction. The patterns were measured on the sample powder placed in $0.7 \mathrm{~mm}$ capillaries. For the in situ synchrotron XRD experiments, about $1 \mathrm{mg}$ of the catalysts powder was heated in a $0.7 \mathrm{~mm}$ outer diameter quartz capillary (Hilgenberg $\mathrm{GmbH}$, Germany) under quasi flowing conditions $\left(\mathrm{CH}_{4}: \mathrm{CO}_{2}: \mathrm{N}_{2}=1: 1: 3\right.$ and $1: 2: 3$ ). The gases were injected through a $0.5 \mathrm{~mm}$ outer diameter tungsten tube. The capillary is heated at a $10{ }^{\circ} \mathrm{C} \mathrm{min}{ }^{-1}$ heating rate in an infrared heated SiC tube furnace as described elsewhere. ${ }^{54,55}$ The patterns were recorded using a PerkinElmer flat panel detector (XRD 1621, dark image, and strain correction). A NIST 660b LaB6 standard was used to calibrate the measurement. Elemental analysis (for $\mathrm{Si}$ and $\mathrm{Ni}$ ) was performed with inductively coupled plasma optical emission spectroscopy (ICPOES) in a Horiba Scientific ICP Ultima2 (Horiba, Japan). The powder samples were digested in an aqueous suspension with the addition of $\mathrm{HNO}_{3}$ and $\mathrm{HF}$ at $200{ }^{\circ} \mathrm{C}$ for $5 \mathrm{~h}$ in an autoclave. The polymer to ceramic conversion was investigated in an argon atmosphere with a heating rate of $5{ }^{\circ} \mathrm{C} \mathrm{min}^{-1}$ with thermal gravimetric analysis (TGA) on a STA 409 PC LUXX (Netzsch, Germany) coupled with a mass spectrometer OMNi Star GSD 320 (Pfeiffer Vacuum, Germany). Solid-state nuclear magnetic resonance (NMR) spectra were recorded with a Bruker Avance $400 \mathrm{MHz}$ spectrometer operating at $100.56 \mathrm{MHz}$ for ${ }^{13} \mathrm{C}, 79.44 \mathrm{MHz}$ for ${ }^{29} \mathrm{Si}$, and $399.88 \mathrm{MHz}$ for ${ }^{1} \mathrm{H} .{ }^{1} \mathrm{H}-{ }^{13} \mathrm{C}$ and ${ }^{1} \mathrm{H}-{ }^{29} \mathrm{Si}$ crosspolarization magic angle spinning (CP-MAS) NMR experiments were carried out at a MAS rate of $10 \mathrm{kHz}$ using a $4 \mathrm{~mm}$ MAS HX double-resonance probe. The ${ }^{1} \mathrm{H} \pi / 2$ pulse length was $3.1 \mu \mathrm{s}$, and two pulse phase modulation (TPPM) heteronuclear dipolar decoupling was used during acquisition. The spectra were measured using a contact time of $2.0 \mathrm{~ms}$ and a recycle delay of 2 s. All ${ }^{13} \mathrm{C}$ and ${ }^{29} \mathrm{Si}$ spectra are referenced to those of external tetramethylsilane (TMS) at $0 \mathrm{ppm}$ for ${ }^{13} \mathrm{C}$ and ${ }^{29} \mathrm{Si}$ using adamantane and tetrakis(trimethylsilyl)silane (TKS) as secondary references, respectively. The finely ground sample powders were inserted into the NMR rotor with a funnel in the glovebox. Transmission electron microscopy (TEM) images and energy-dispersive X-ray spectroscopy (EDX) spectra were obtained using an FEI Tecnai G2 20 S-TWIN equipped with a LaB6-source at $200 \mathrm{keV}$ acceleration voltage (FEI, USA). The samples for TEM analysis were prepared in the glovebox by dispersion in anhydrous THF, followed by dropping them onto a copper grid covered with a carbon film. Particle size distribution was calculated from TEM images using the Nano measurer software by quantifying 100 particles. X-ray absorption near-edge spectroscopy (XANES) was performed in the transmission mode at beamline KMC-2 of the BESSY-II synchrotron light source at Berlin, Germany, equipped with a graded $\mathrm{Si}-\mathrm{Ge}(111)$ double crystal monochromator to characterize the oxidation states of $\mathrm{Ni}$ in the synthesized Ni-containing precursors. ${ }^{56}$ The samples were prepared in the form of powder applied onto adhesive Kapton tape. High harmonics were rejected 
by detuning the monochromator so that the intensity of the beam on the samples was $65 \%$ of the maximum possible intensity. Reference spectra were simultaneously measured for energy calibration. X-ray absorption fine structure (XAFS) measurements were carried out with a novel self-developed wavelengthdispersive spectrometer in von Hámos geometry to characterize the oxidation states of $\mathrm{Ni}$ in the pyrolyzed Ni/SiOCN ceramic nanocomposites. ${ }^{57}$ The spectrometer was equipped with a microfocus X-ray tube, a curved Highly Annealed Pyrolytic Graphite mosaic crystal, and a hybrid photon counting CMOS detector with $512 \times 1030$ pixel and a pixel size of $75 \mu \mathrm{m} \times 75 \mu \mathrm{m}$. The tube was operated with a high voltage of $16 \mathrm{kV}$ and a current of $200 \mu \mathrm{A}$. The references ( $\mathrm{Ni}$ foil, $\mathrm{Ni}_{2} \mathrm{Si}$, and $\mathrm{NiO}$ ) were prepared as powders on scotch tape while the samples were prepared as wax-pellets (with Hoechst wax C), due to their lower concentration of $\mathrm{Ni}$, with $13 \mathrm{~mm}$ pellet diameter. All references and samples were constantly moved during the measurements to minimize the effects of local thickness inhomogeneity. The beam size on the samples was around $3 \mathrm{~mm} \times 3 \mathrm{~mm}$. The gathered spectral range covered the Ni K absorption edge at $8332 \mathrm{eV}$. The EXAFS evaluation was performed by using the Demeter software. ${ }^{58}$ Nitrogen sorption measurements were carried out using a QuadraSorb Station 4 apparatus (Quantachrome, USA). Isotherms were recorded at $77 \mathrm{~K}$ after degassing under vacuum at $150{ }^{\circ} \mathrm{C}$ for $12 \mathrm{~h}$ before the actual measurement. The surface area was calculated using Brunauer-Emmett-Teller (BET) calculations. All nitrogen sorption data were analyzed using the Quantachrome/QuadraWin software version 5.05.

\section{Results and discussion}

\section{Chemical structure and formation mechanisms of the synthesized Ni-containing polysilazane precursors}

As displayed in Fig. 1, the ATR-FTIR spectrum of Durazane 1800 shows the characteristic absorption bands of poly(vinyl)silazane: the bands attributed to - $\mathrm{Si}-\mathrm{NH}-\mathrm{Si}$ - groups such as $\mathrm{N}-\mathrm{H}$ stretching at $3382 \mathrm{~cm}^{-1}$ and the vibration of the $\mathrm{NH}$ unit bridging two

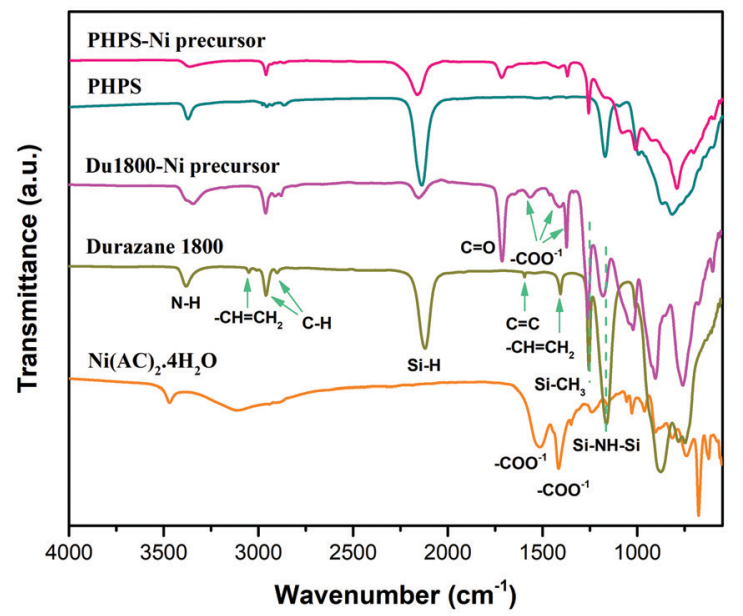

Fig. 1 The ATR-FTIR spectra of Du1800-Ni and PHPS-Ni precursors along with reactants $\mathrm{Ni}(\mathrm{Ac})_{2} \cdot 4 \mathrm{H}_{2} \mathrm{O}$, Durazane 1800, and PHPS. silicon atoms at $1162 \mathrm{~cm}^{-1}$. The bands related to vinyl silyl groups $\left(\mathrm{CH}_{2}=\mathrm{CH}-\mathrm{Si}-\right)$ are also observed as $\mathrm{C}-\mathrm{H}$ vibrations at 3042 and $3006 \mathrm{~cm}^{-1}, \mathrm{C}=\mathrm{C}$ stretching at $1590 \mathrm{~cm}^{-1}$, and scissoring of terminal methylene at $1402 \mathrm{~cm}^{-1}$. The strong absorption band assigned to $\mathrm{Si}-\mathrm{H}$ vibration appears at $2116 \mathrm{~cm}^{-1}$. The main characteristic band of $\mathrm{Si}-\mathrm{CH}_{3}$ groups is located at $1255 \mathrm{~cm}^{-1}$ with two bands at 2953 and $2896 \mathrm{~cm}^{-1}$ corresponding to the C-H stretching. ${ }^{44,59}$ Similarly, the ATRFTIR spectrum of PHPS shows the bands associated with $\mathrm{N}-\mathrm{H}$ (3382 $\left.\mathrm{cm}^{-1}\right), \mathrm{Si}-\mathrm{H}\left(2146 \mathrm{~cm}^{-1}\right)$ and $\mathrm{Si}-\mathrm{NH}-\mathrm{Si}\left(1170 \mathrm{~cm}^{-1}\right)$. A remarkable decrease in the intensity of absorption bands corresponding to $\mathrm{Si}-\mathrm{H}$ and $-\mathrm{NH}-$ (in $-\mathrm{Si}-\mathrm{NH}-\mathrm{Si}-$ ) groups is observed in the ATR-FTIR spectra of synthesized Du1800-Ni and PHPS-Ni precursors. Moreover, new bands related to the $\mathrm{C}=\mathrm{O}$ vibration (1712 $\mathrm{cm}^{-1}$ ) and acetate group (1561, 1414, and $1368 \mathrm{~cm}^{-1}$ ) are detected in the spectra of both precursors. The absorption bands corresponding to $\mathrm{C}=\mathrm{O}$ vibration can be mainly attributed to the formed $\mathrm{Si}-\mathrm{OOCCH}_{3}$ in the synthesized precursors. These results suggest the successful chemical reaction between the nickel acetate tetrahydrate with both polymers. ${ }^{46}$ Additionally, for the synthesized Du1800-Ni precursor, the absorption bands at 3042 and $3006 \mathrm{~cm}^{-1}$ that were attributed to the vinyl groups vanished, which can be explained by a hydrosilylation reaction between $\mathrm{Si}-\mathrm{H}$ and $-\mathrm{Si}-\mathrm{CH}=\mathrm{CH}_{2}$. Although the hydrosilylation reaction usually takes place at $T>120{ }^{\circ} \mathrm{C}$ in pure polysilazanes, ${ }^{60,61}$ previous works showed that the presence of inorganic catalysts such as transition metals or metal complexes could remarkably lower this reaction temperature. ${ }^{44,46}$

The chemical structure of the Du1800-Ni precursor was further confirmed by ${ }^{13} \mathrm{C}\left\{{ }^{1} \mathrm{H}\right\}$ and ${ }^{29} \mathrm{Si}\left\{{ }^{1} \mathrm{H}\right\}$ CPMAS NMR characterization (Fig. 2). As displayed in Fig. 2a, the ${ }^{13} \mathrm{C}\left\{{ }^{1} \mathrm{H}\right\}$ CPMAS NMR spectrum of the Du1800-Ni precursor shows the characteristic signal shift of the $\mathrm{CH}_{3} \mathrm{COO}-$ group with a chemical shift at $20 \mathrm{ppm}\left(-\mathrm{CH}_{3}\right)$ and $167 \mathrm{ppm}(\mathrm{C}=\mathrm{O})$, which are not observed for Durazane 1800 (Fig. S4, ESI $\dagger$ ). Moreover, the NMR signals corresponding to vinyl groups $\left(-\mathrm{CH}=\mathrm{CH}_{2}{ }^{-}\right)$, which are found between 128 and $142 \mathrm{ppm}$ in the spectrum of Durazane 1800, vanish in the synthesized precursor. ${ }^{62}$ These results confirm the chemical reaction between nickel acetate tetrahydrate and polymer as well as the hydrosilylation reaction between $-\mathrm{CH}_{2}=\mathrm{CH}_{2}-$ and $\mathrm{Si}-\mathrm{H}$ groups, which agrees with ATR-FTIR results. The NMR signals between -10 and $4 \mathrm{ppm}$ in the spectra of Durazane 1800 and Du1800-Ni precursor can be assigned to the carbon atoms of aliphatic groups bonded to a silicon atom $\left(\mathrm{Si}-\mathrm{CH}_{3}\right)$. These results are also in accordance with the ${ }^{29} \mathrm{Si}\left\{{ }^{1} \mathrm{H}\right\}$ CPMAS NMR spectrum (Fig. 2b), which shows the presence of $\mathrm{Si}\left(\mathrm{CH}_{3}\right)\left(\mathrm{CH}_{2} \mathrm{CH}_{2}\right) \mathrm{N}_{2}$ and $\mathrm{Si}\left(\mathrm{CH}_{3}\right)(\mathrm{H}) \mathrm{N}_{2}$ units in the synthesized Du1800-Ni precursor at -8 and $-25 \mathrm{ppm}$, respectively. ${ }^{63,64}$ The weak signal observed at $-35 \mathrm{ppm}$ can be assigned to the residue $\mathrm{Si}\left(\mathrm{CH}=\mathrm{CH}_{2}\right) \mathrm{N}_{3}$ units in the Du1800-Ni precursor. ${ }^{63,65,66}$ The signals between -40 and -60 ppm might be owed to $\mathrm{Si}-\mathrm{OOCCH}_{3} .{ }^{67}$

The oxidation states of incorporated nickel on the surface of synthesized Ni-containing precursors were investigated by X-ray photoelectron spectroscopy (XPS). As shown in Fig. 3, XPS $\mathrm{Ni} 2 \mathrm{p}$ spectra of Du1800-Ni and PHPS-Ni precursors can be 

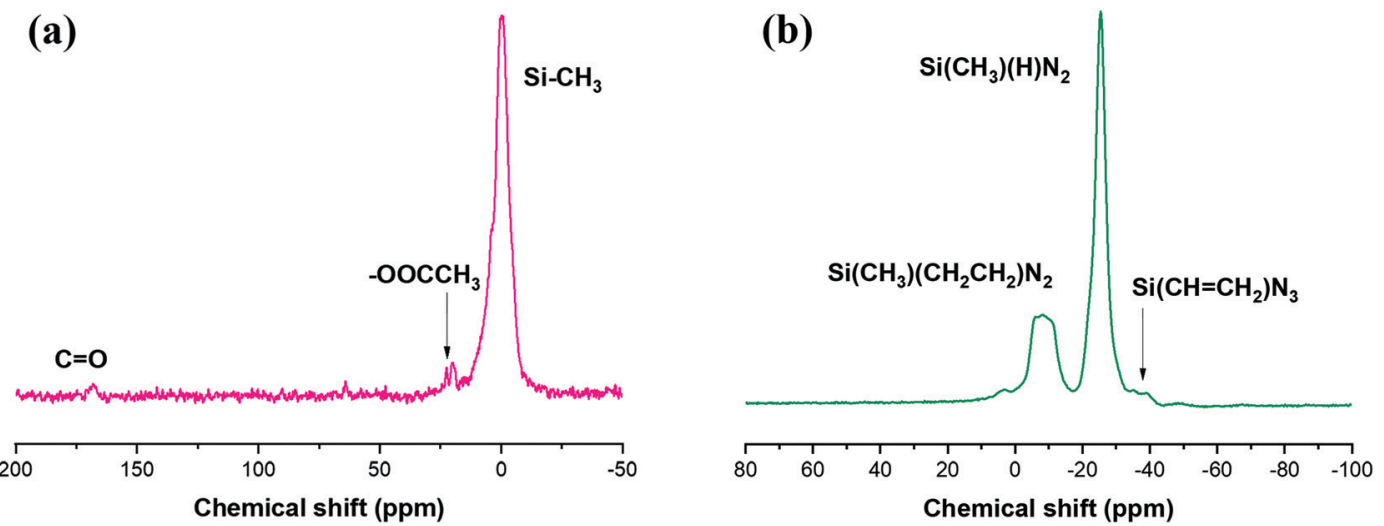

Fig. 2 The (a) ${ }^{13} \mathrm{C}\left\{{ }^{1} \mathrm{H}\right\}$ CPMAS and (b) ${ }^{29} \mathrm{Si}\left\{{ }^{1} \mathrm{H}\right\}$ CPMAS NMR spectra of the Du1800-Ni precursor.

deconvoluted into two doublet peaks characteristic of $2 \mathrm{p}_{1 / 2}$ and $2 \mathrm{p}_{3 / 2}$ spin-orbit splitting. The doublet peak observed at 852.7 and $869.9 \mathrm{eV}$ can be assigned to metallic $\mathrm{Ni}^{0}$, while the doublet at 855.5 and $872.7 \mathrm{eV}$ can be attributed to $\mathrm{Ni}^{2+}$. The broad peaks at 861.1 and $877.0 \mathrm{eV}$ are satellite peaks corresponding to $\mathrm{Ni} 2 \mathrm{p}_{3 / 2}$ and $2 \mathrm{p}_{1 / 2}$, respectively, which is in good agreement with previous reports on metallic $\mathrm{Ni}$ and $\mathrm{NiO}$ compounds. ${ }^{68-70}$ These results suggest the in situ formation of metallic Ni during the reaction between nickel acetate tetrahydrate and poly(vinyl)silazane Durazane 1800 or PHPS polymers. Most probably, the surface of metallic Ni nanoparticles formed in both precursors (as indicated by TEM, see below) is oxidized to $\mathrm{Ni}^{2+}$.

The oxidation states of nickel in the synthesized $\mathrm{Ni}$ containing precursors were further confirmed by X-ray absorption near-edge spectra (XANES) characterization. Fig. 4a shows the normalized Ni K-edge XANES spectra of Du1800-Ni and PHPS-Ni precursors as well as those of Ni compounds used as reference materials. The first derivative spectra of the XANES are shown in Fig. $4 \mathrm{~b}$. The pre-edge peak, which depends on the oxidation states of the $3 \mathrm{~d}$ transition element, ${ }^{71,72}$ in the synthesized Du1800-Ni and PHPS-Ni precursors is located at energies between those of reference $\mathrm{Ni}^{0}$ foil $(8333 \mathrm{eV})$ and $\mathrm{Ni}^{2+}(\mathrm{Ac})_{2}$. $4 \mathrm{H}_{2} \mathrm{O} / \mathrm{Ni}^{2+} \mathrm{O}(8331 \mathrm{eV})$ references. This indicates that nickel oxidation states in the synthesized precursors are between $\mathrm{Ni}^{0}$ and $\mathrm{Ni}^{2+}$, which is consistent with the XPS results (Fig. 3). Nanocrystalline nickel particles in the synthesized Du1800-Ni precursor is also confirmed by the high-resolution XRD patterns (Fig. S6a, ESI $\dagger$ and Fig. 13a). The high-resolution XRD pattern of the Du1800-Ni precursor manifests clear reflections of the metallic nickel phase (ICDD-PDF-00-004-0850), while that of the PHPS-Ni precursor exhibits an amorphous structure (Fig. S6b, ESI, $\dagger$ and Fig. 13b).

As revealed by the TEM characterization, the Du1800-Ni precursor consists of homogeneously distributed nickel nanoparticles (Fig. 5a) with an average size of $\sim 2.4 \mathrm{~nm}$ (Fig. 5c) in an amorphous polymer matrix. In contrast, although nickel nanoparticles are not observed in the PHPS-Ni precursor (Fig. 5b), EDX analysis shows the presence of the nickel element in the amorphous polymer matrix (Fig. 5d). This result can be due to the too tiny size of formed nickel nanoparticles to be observed, which agrees with high-resolution XRD results (see the next section). The particle size of nickel in this sample is found to be $\sim 2.5 \mathrm{~nm}$ even after pyrolyzing at $700{ }^{\circ} \mathrm{C}$ in an argon atmosphere (see the next section). The incorporation of metallic $\mathrm{Ni}$ and $\mathrm{Ni}^{2+}$-compounds in the PHPS-Ni precursor is also confirmed by XPS (Fig. 3) and XANES (Fig. 4) results.
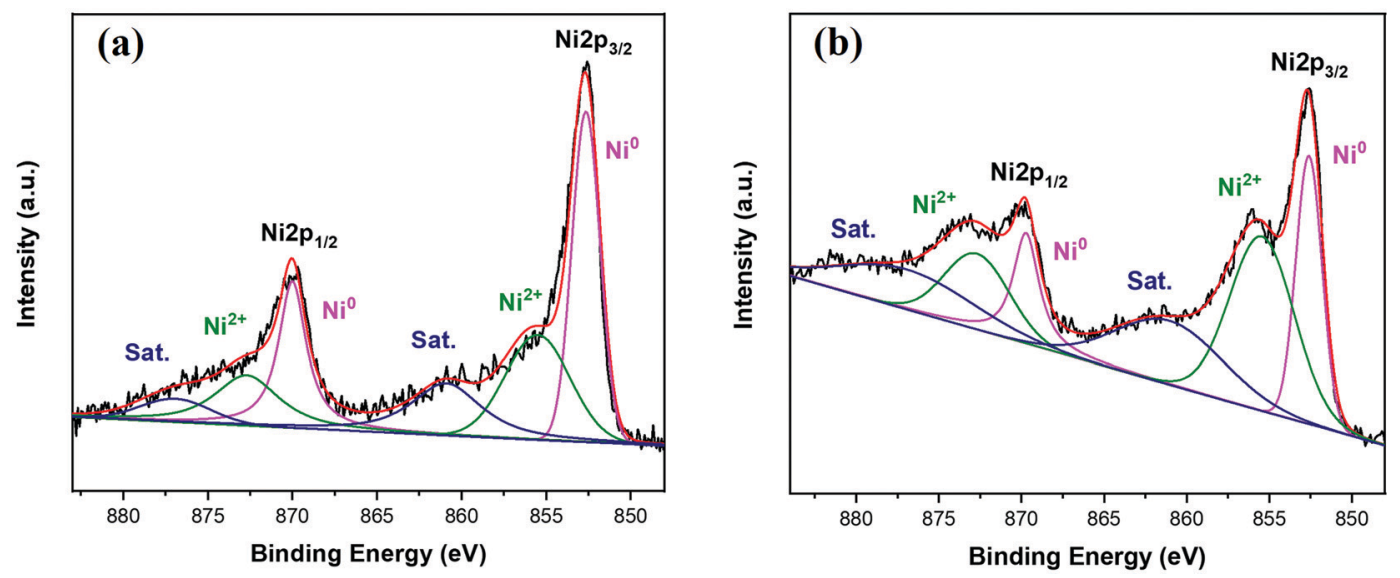

Fig. 3 The Ni 2p X-ray photoelectron spectra of (a) Du1800-Ni and (b) PHPS-Ni precursors. Sat. denotes the satellite peaks. 

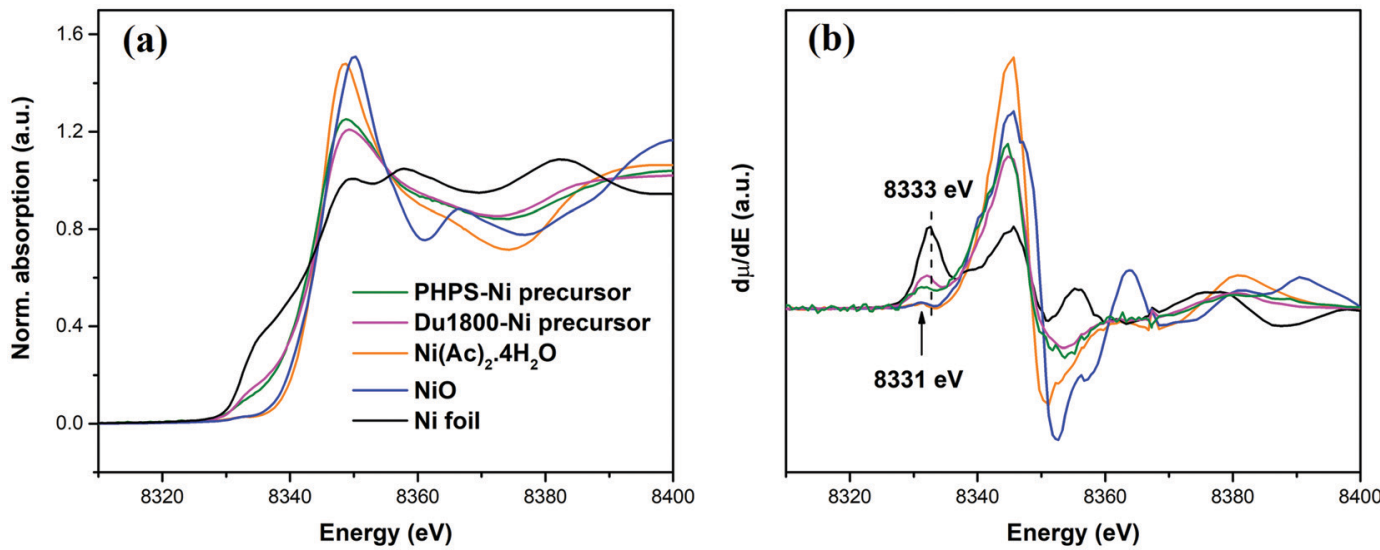

Fig. 4 (a) The normalized Ni K-edge XANES spectra and (b) the corresponding first derivative of Du1800-Ni and PHPS-Ni precursors as well as reference materials $\left(\mathrm{Ni}^{0}\right.$ foil, $\mathrm{Ni}^{2+} \mathrm{O}$, and $\left.\mathrm{Ni}^{2+}(\mathrm{Ac})_{2} \cdot 4 \mathrm{H}_{2} \mathrm{O}\right)$.

According to ATR-FTIR, ${ }^{13} \mathrm{C}\left\{{ }^{1} \mathrm{H}\right\}$ and ${ }^{29} \mathrm{Si}\left\{{ }^{1} \mathrm{H}\right\}$ CPMAS NMR, XPS, XANES, XRD, and TEM characterization, the mechanisms involved in the reaction of $\mathrm{Ni}(\mathrm{Ac})_{2} \cdot 4 \mathrm{H}_{2} \mathrm{O}$ with poly(vinyl)silazane Durazane 1800 can be explained as follows. As shown in Fig. 6, the acetate groups of $\mathrm{Ni}(\mathrm{Ac})_{2} \cdot 4 \mathrm{H}_{2} \mathrm{O}$ react first with $\mathrm{Si}-\mathrm{H}$ groups of Durazane 1800, causing the formation of acetosilyl groups
$\left(\mathrm{CH}_{3} \mathrm{COO}-\mathrm{Si}-\right)$, Ni nanoparticles, and $\mathrm{H}_{2}$ gas. The in situ formation of metallic Ni nanoparticles in this step might be due to electron transfer from negatively charged hydrogen in $-\mathrm{Si}-\mathrm{H}$ to $\mathrm{Ni}^{2+}$ in the $\mathrm{Ni}\left(\right.$ II) acetate that results in $\mathrm{Ni}^{2+}$ reduction with in situ formation of metallic Ni nanoparticles, $\mathrm{H}_{2}$ evolution, and formation of acetic acid. Then the formed acetic acid might react with
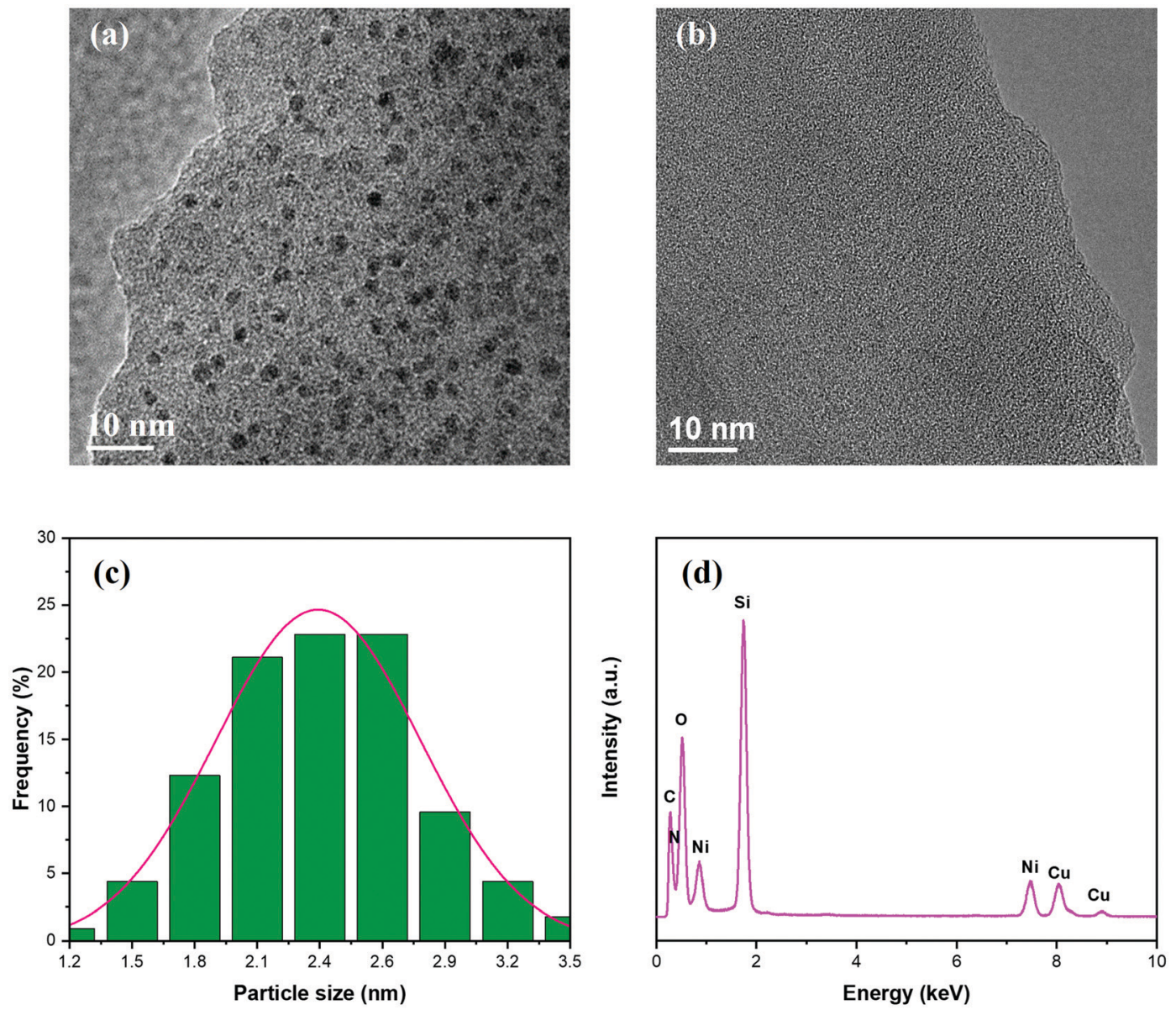

Fig. 5 TEM images of (a) Du1800-Ni and (b) PHPS-Ni precursors. (c) The particle size distribution of formed nickel nanoparticles in the Du1800-Ni precursor. (d) EDX spectrum of the PHPS-Ni precursor. 

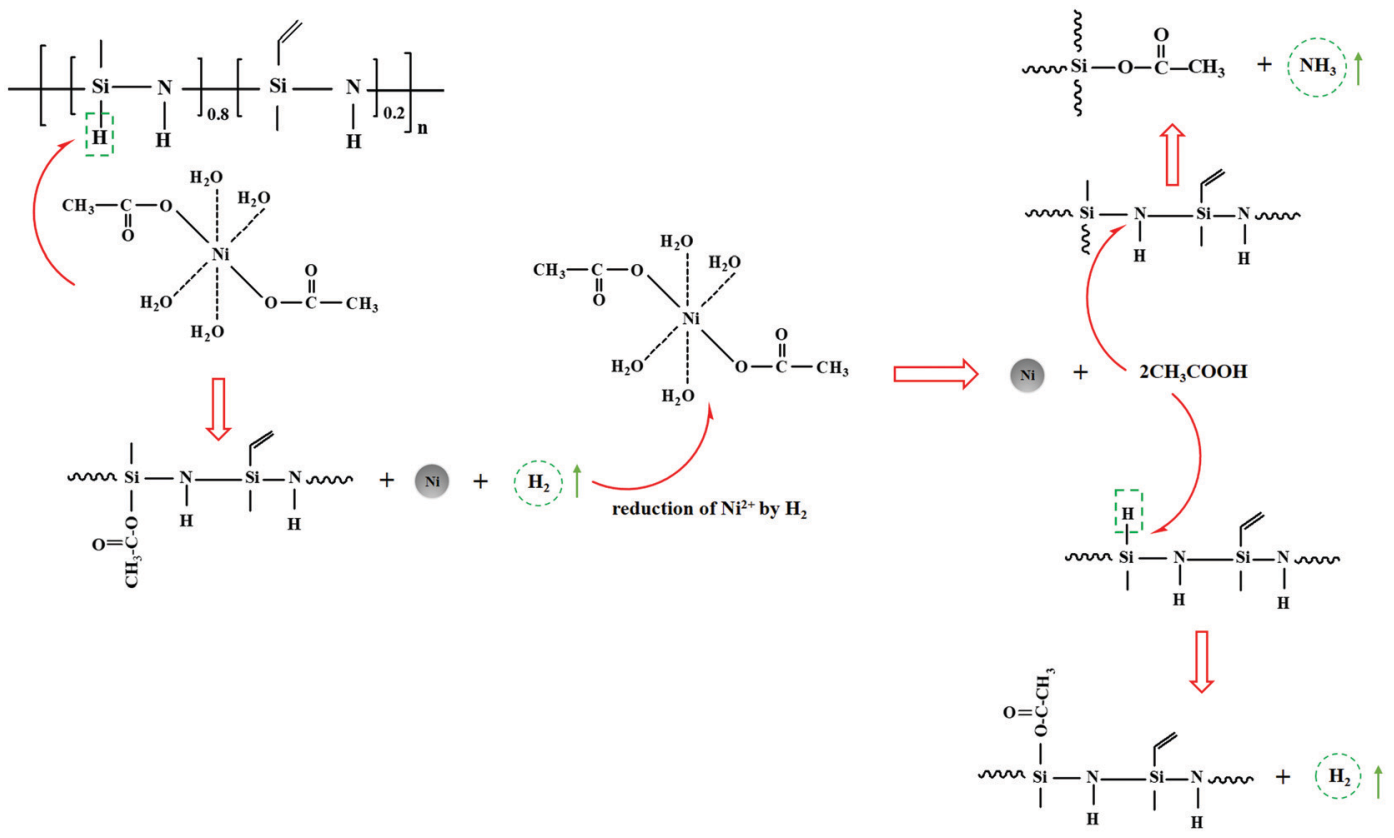

Fig. 6 Schematic of possible mechanisms of reaction between poly(vinyl)silazane Durazane 1800 and $\mathrm{Ni}(\mathrm{Ac})_{2} \cdot 4 \mathrm{H}_{2} \mathrm{O}$ that leads to the formation of metallic nickel nanoparticles.

$-\mathrm{Si}-\mathrm{H}$ and $-\mathrm{Si}-\mathrm{NH}-\mathrm{Si}-$ groups of Durazane 1800, releasing gaseous $\mathrm{H}_{2}$ and $\mathrm{NH}_{3}$, respectively. The release of gaseous $\mathrm{H}_{2}$ and $\mathrm{NH}_{3}$ during the reaction is confirmed by gas chromatography (Fig. S5, ESI $\dagger$ ), and $\mathrm{HCl}$ titration, respectively. Moreover, gaseous bubbles and changes in solution color are observed during this chemical reaction (Fig. S2, ESI $\dagger$ ). Our finding is in line with recently proposed mechanisms for the endothermic reaction of polysilazanes with carboxy end groups of the unsaturated polyesters. ${ }^{73}$ This proposed reaction mechanism also agrees with our previous report on the mechanism involved in the reaction of polysilazane HTT1800 with trans-[bis(2-aminoethanol- $N, O$ )diacetatonickel(II)]. ${ }^{44}$ As PHPS consists also of active groups such as $-\mathrm{Si}-\mathrm{H}$ and -Si-NH-Si- (Fig. S3, ESI $\dagger$ ), similar reaction mechanisms might be involved in its reaction with $\mathrm{Ni}(\mathrm{Ac})_{2} \cdot 4 \mathrm{H}_{2} \mathrm{O}$. However, a hydrosilylation reaction between $-\mathrm{Si}-\mathrm{H}$ and $-\mathrm{Si}-\mathrm{CH}=\mathrm{CH}_{2}$ groups in Durazane 1800 might take place under these reaction conditions, forming carbosilane bonds (-Si- $\left.\mathrm{CH}_{2}-\mathrm{CH}_{2}-\mathrm{Si}-\right)$ in the synthesized Du1800-Ni precursor.

\section{The transformation of Du1800-Ni and PHPS-Ni precursors into $\mathrm{Ni} /$ SiOCN ceramic nanocomposites}

The pyrolysis of Du1800-Ni (Fig. 7a and b) and PHPS-Ni (Fig. 7c and d) precursors is accompanied by the evolution of gaseous $\mathrm{H}_{2}(m / z=2), \mathrm{CH}_{4}(m / z=16), \mathrm{NH}_{3}(m / z=17)$ and $\mathrm{CO}_{2}(m / z=44)$ as well as the distillation of oligomer fragments $(\mathrm{m} / \mathrm{z}=41,42$, $52,55)$. For the Du1800-Ni precursor, the $\mathrm{NH}_{3}$ evolution corresponds to the transamination reaction and $\mathrm{CH}_{4}$ evolution originates from the decomposition of $\mathrm{Si}-\mathrm{CH}_{3}, \mathrm{Si}-\mathrm{OOCCH}_{3}$, or the cleavage of $\mathrm{C}-\mathrm{C}$ bonds, both cause the weight loss of $\sim 17 \%$ at $T<500{ }^{\circ} \mathrm{C}$. Since the PHPS polymer does not contain carbon in its backbone chain, $\mathrm{CH}_{4}$ evolution should be attributed to the decomposition of side groups (i.e. $-\mathrm{Si}-\mathrm{OOCCH}_{3}$ units) in the PHPS-Ni precursor. This suggestion is confirmed by detecting $\mathrm{CHCO}^{+}(\mathrm{m} / \mathrm{z}=41)$ and $\mathrm{CH}_{2} \mathrm{CO}^{+}(\mathrm{m} / \mathrm{z}=42)$ ions in the same temperature range (see Fig. $7 \mathrm{~b}$ and d). A high amount of $\mathrm{H}_{2}$ is released during the cross-linking of the PHPS-Ni precursor and the weight loss is $\sim 7 \%$ at $T<500{ }^{\circ} \mathrm{C}$, which is much lower than that observed for the Du1800-Ni precursor. The $\mathrm{CH}_{4}$ evolution and $\mathrm{H}_{2}$ evolution due to the dehydrocoupling reaction of $\mathrm{Si}-\mathrm{H} / \mathrm{Si}-$ $\mathrm{H}$ and $\mathrm{Si}-\mathrm{H} / \mathrm{N}-\mathrm{H}$ groups are responsible for the weight loss of $\sim 8$ and $5 \%$ at $T>500{ }^{\circ} \mathrm{C}$ for Du1800-Ni and PHPS-Ni precursors, respectively. These results differ significantly from those reported for the pyrolysis of unmodified Durazane 1800 and PHPS polymers. ${ }^{46,74}$ For instance, the gaseous $\mathrm{NH}_{3}$ and $\mathrm{H}_{2}$ evolved below $200{ }^{\circ} \mathrm{C}$ for Du1800-Ni and PHPS-Ni precursors were not observed during the thermolysis of unmodified polymers. These results can be explained by the desorption of gaseous $\mathrm{NH}_{3}$ and $\mathrm{H}_{2}$ that are formed during the synthesis process (see Fig. 6) and adsorbed on the surface of the Ni-containing precursors. Besides, the hydrocarbon oligomers $(\mathrm{m} / \mathrm{z}=52$ and 55) detected in the temperature range of $200-400{ }^{\circ} \mathrm{C}$ are not observed during the pyrolysis of unmodified polymers. This result suggests that the in situ formed metallic nickel nanoparticles in the precursors might catalyze the formation of these hydrocarbons. In addition, the cross-linking and polymer-ceramic transformation processes are completed at 900 and $700{ }^{\circ} \mathrm{C}$ for Durazane 1800 and PHPS polymers, respectively. In contrast, for Du1800-Ni and PHPS-Ni precursors, the weight losses are observed with the evolution of $\mathrm{H}_{2}$ up to $1100{ }^{\circ} \mathrm{C}$. This finding can be explained by the activation of dehydrogenation reactions by nickel nanoparticles. Finally, Du1800-Ni and PHPS-Ni precursors show a ceramic yield of $\sim 75$ and $88 \%$, respectively, which is much higher than reported values for unmodified Durazane $1800(\sim 66 \%)$ and PHPS $(\sim 80 \%)$ polymers. ${ }^{46,74}$ These results can be explained by the increased 

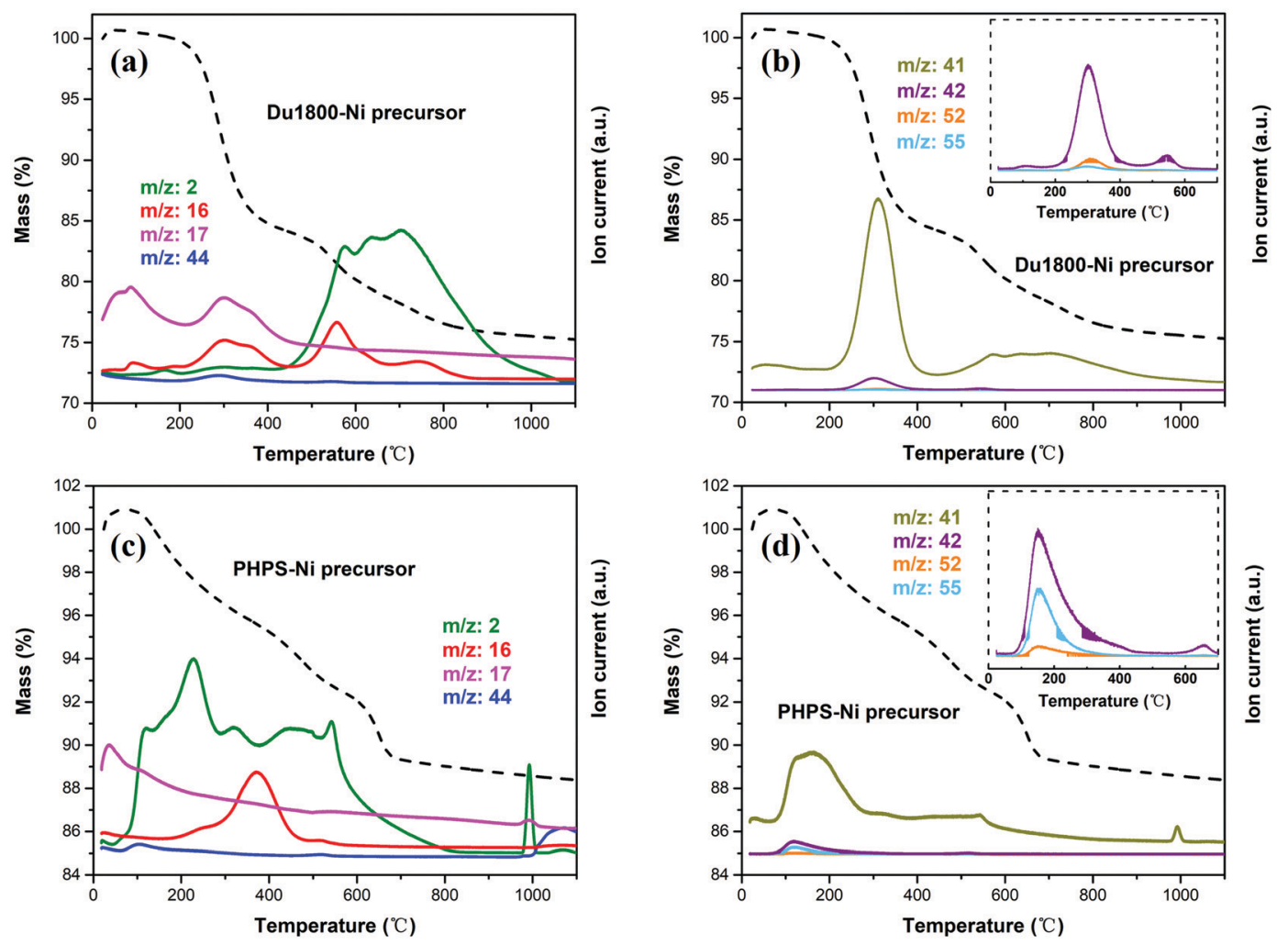

Fig. 7 Results of simultaneous thermal gravimetric (dashed lines) and mass spectrometry analysis of (a and b) Du1800-Ni and (c and d) PHPS-Ni precursors.

cross-linking degree of the polymer upon chemical modification with nickel acetate tetrahydrate (see Fig. 6).

The cross-linking and polymer-ceramic transformation processes of Du1800-Ni and PHPS-Ni precursors were further confirmed by ATR-FTIR characterization. Fig. 8 shows the ex situ ATR-FTIR spectra of ceramic nanocomposites derived from Du1800-Ni and PHPS-Ni precursors by pyrolyzing at different temperatures under an argon atmosphere for $3 \mathrm{~h}$. The intensity of absorption bands corresponding to $\mathrm{N}-\mathrm{H}\left(3343 \mathrm{~cm}^{-1}\right), \mathrm{C}-\mathrm{H}$ $\left(2960 \mathrm{~cm}^{-1}\right), \mathrm{Si}-\mathrm{H}\left(2152 \mathrm{~cm}^{-1}\right), \mathrm{C}=\mathrm{O}\left(1712 \mathrm{~cm}^{-1}\right)$, and $-\mathrm{COO}^{-1}$ (1610-1330 $\mathrm{cm}^{-1}$ ) gradually decreases with increasing pyrolysis temperature. For the Du1800-Ni precursor that pyrolyzed at 900 and $1100{ }^{\circ} \mathrm{C}$, broad absorption bands attributed to $\mathrm{Si}-\mathrm{O}\left(1026 \mathrm{~cm}^{-1}\right)$, $\mathrm{Si}-\mathrm{N}\left(904 \mathrm{~cm}^{-1}\right)$, and $\mathrm{Si}-\mathrm{C}\left(766 \mathrm{~cm}^{-1}\right)$ are observed, suggesting the formation of SiOCN ceramic. As shown in Fig. 8b, the formation of SiOCN in the PHPS-Ni precursor occurs at lower pyrolysis temperature $\left(700^{\circ} \mathrm{C}\right)$ than that of the Du1800-Ni precursor $\left(900{ }^{\circ} \mathrm{C}\right)$, which agrees with the results of TG-MS analysis (Fig. 7).
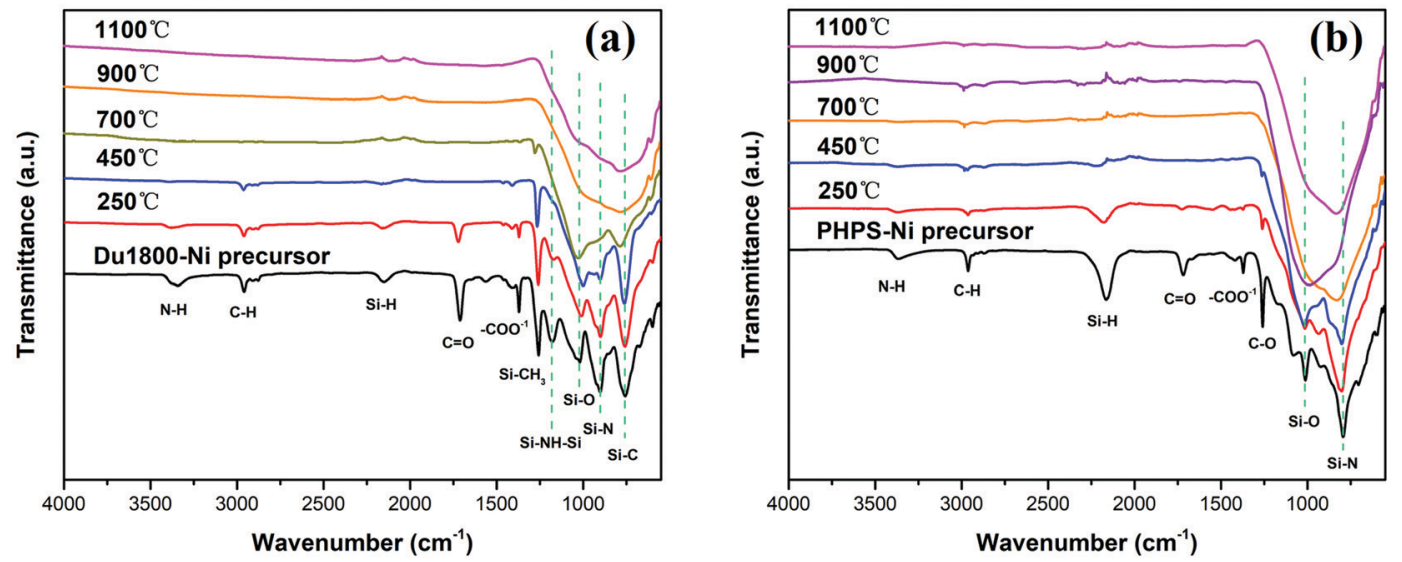

Fig. 8 ATR-FTIR spectra of (a) Du1800-Ni and (b) PHPS-Ni precursors thermally treated at $250{ }^{\circ} \mathrm{C}, 450{ }^{\circ} \mathrm{C}, 700{ }^{\circ} \mathrm{C}, 900{ }^{\circ} \mathrm{C}$, and $1100{ }^{\circ} \mathrm{C}$ under an argon atmosphere for $3 \mathrm{~h}$. 


\section{Chemical composition and structure of Ni/SiOCN ceramic nanocomposites}

In the next step, the chemical and phase compositions of $\mathrm{Ni} / \mathrm{SiOCN}$ ceramic nanocomposites obtained by the pyrolysis of synthesized Ni-containing precursors at 700, 900, and $1100{ }^{\circ} \mathrm{C}$ under an argon atmosphere for $3 \mathrm{~h}$ were characterized using ICP-OES, XRD, XAFS, and TEM techniques. As shown in Table S1 (ESI $\dagger$ ), the weight ratio $\mathrm{Si} / \mathrm{Ni}$ in the pyrolyzed Du1800$\mathrm{Ni}$ and PHPS-Ni samples is $4.1 \pm 0.1$ and $6.3 \pm 0.1$, respectively, regardless of the pyrolysis temperatures. In contrast, the analysis of the X-ray photoelectron spectra survey reveals that the surface composition (especially $\mathrm{C}, \mathrm{O}$, and $\mathrm{N}$ amount) varies significantly with the pyrolysis temperature (see Tables S2 and S3, ESI $\dagger$ ). These results are in good agreement with TG-MS analysis, which indicates the continuous evolution of gaseous species that in turn causes composition changes during the pyrolysis of precursors up to $1100{ }^{\circ} \mathrm{C}$.

As shown in Fig. S6a (ESI $\dagger$ ), the high-resolution XRD pattern of the 700Ar-Du1800-Ni sample obtained by pyrolysis of the Du1800-Ni precursor at $700{ }^{\circ} \mathrm{C}$ under an argon atmosphere reveals the presence of graphitic carbon (ICDD-PDF-03-0656212) and nanocrystalline metallic nickel (ICDD-PDF-00-0040850). The latter reacts partially with the SiOCN matrix at higher pyrolysis temperatures to form the nickel silicide $\mathrm{Ni}_{2} \mathrm{Si}$ (ICDD-PDF-00-048-1339) phase in 900Ar-Du1800-Ni and 1100Ar-Du1800-Ni samples. In addition to the $\mathrm{Ni}_{2} \mathrm{Si}$ phase, crystalline $\mathrm{SiC}$ (ICDD-PDF-00-049-1428) is formed in the 1100Ar-Du1800-Ni sample. Although the formation of SiC in polymer-derived ceramics usually takes place at temperatures higher than $1400{ }^{\circ} \mathrm{C},{ }^{75}$ previous works reported that manganese and iron could act as catalysts and lower its formation temperature to $1100{ }^{\circ} \mathrm{C} .{ }^{46}$ For 700Ar-PHPS-Ni and 900Ar-PHPS-Ni samples, only nanocrystalline metallic nickel is detected in their XRD patterns, while nickel silicide $\mathrm{Ni}_{2} \mathrm{Si}$ (ICDD-PDF-00048-1339) and NiSi (ICDD-PDF-00-038-0844) phases are formed in the 1100Ar-PHPS-Ni sample by increasing the pyrolysis temperature to $1100{ }^{\circ} \mathrm{C}$ (Fig. S6b, ESI $\dagger$ ). The XRD reflections corresponding to the metallic Ni phase in PHPS-Ni samples are much broader than those of the same phase in Du1800-Ni samples, suggesting the smaller crystallite sizes of Ni in PHPSNi samples. These results are in good agreement with the TEM characterization, as discussed below.

X-ray absorption fine structure (XAFS) measurements were conducted to obtain further information about phase compositions in the pyrolyzed samples. The Ni K-edge XAFS spectra of pyrolyzed samples, as well as nickel compounds ( $\mathrm{Ni}, \mathrm{Ni}_{2} \mathrm{Si}$, and $\mathrm{NiO}$ ), used as reference materials, are shown in Fig. 9. As shown in Fig. S7 (ESI $\dagger$ ), the linear combination fitting (LCF) of normalized Ni K-edge XAFS spectra of pyrolyzed samples with those reference materials confirms the presence of both metallic $\mathrm{Ni}$ and $\mathrm{Ni}_{2} \mathrm{Si}$ phases in all samples. The weight ratio $\mathrm{Ni}_{2} \mathrm{Si} / \mathrm{Ni}$ in pyrolyzed Du1800-Ni and PHPS-Ni samples is found to increase with increasing pyrolyzing temperature, which agrees with the XRD results. Additionally, small weight fractions of the NiO phase $(\leq 12 \mathrm{wt} \%)$ are found in all samples. No NiO phase is detected by XRD characterization, which might be due to its low crystallinity or amorphous structure.

The results of TEM characterization of 700Ar-Du1800-Ni (Fig. 10a and b) and 700Ar-PHPS-Ni (Fig. 10d and e) samples, as well as EDX mapping of the 1100Ar-Du1800-Ni sample (Fig. S9, ESI $\dagger$ ) confirm the homogeneous distribution of $\mathrm{Ni}$ nanoparticles in the amorphous SiOCN matrix. The average size of the nanoparticles in 700Ar-Du1800-Ni and 700Ar-PHPS-Ni samples is around 3.6 and $2.5 \mathrm{~nm}$, respectively (Fig. 10c and f). Turbostratic carbon is observed only in the 700Ar-Du1800-Ni sample (Fig. 10b), which agrees with XRD results (Fig. S6a, ESI $\dagger$ ). Raman spectra also confirm the formation of turbostratic carbon, which is characterized by the D and G bands, ${ }^{76}$ in all pyrolyzed Du1800-Ni samples (Fig. S8, ESI $\dagger$ ). In contrast, for those samples derived from the PHPS-Ni precursor, both D and G peaks are not
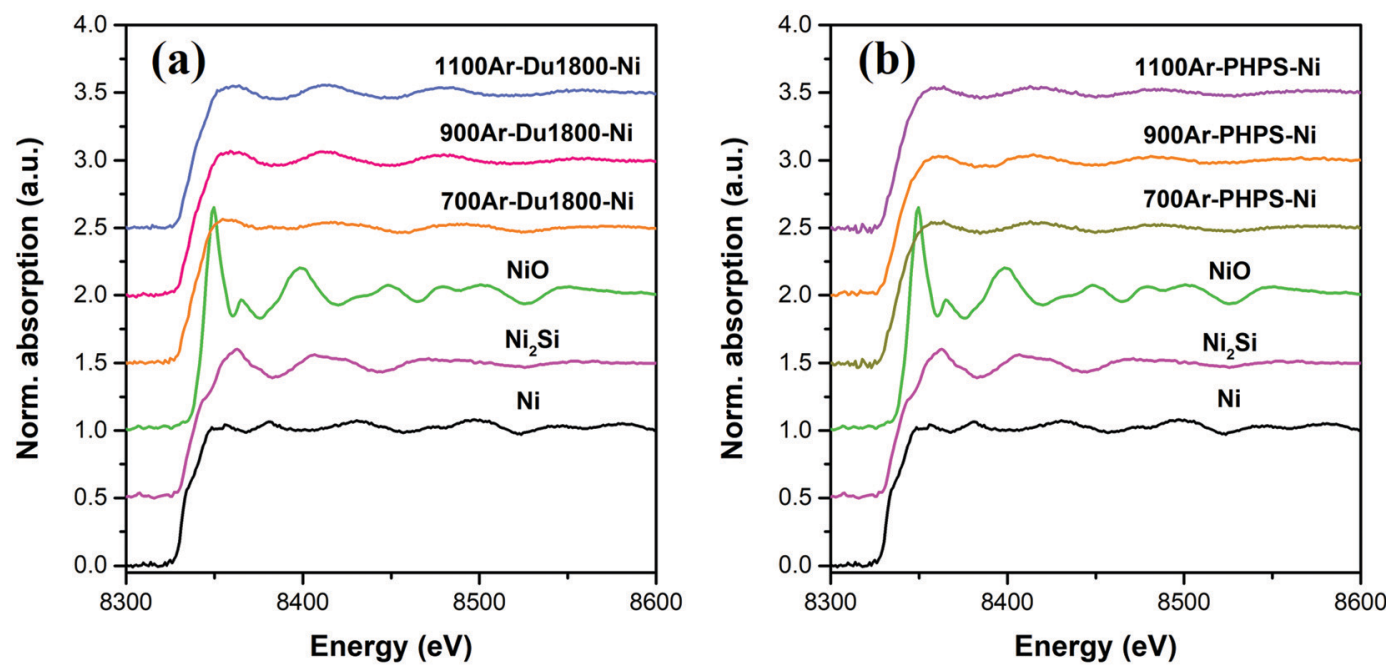

Fig. 9 The Ni K-edge X-ray absorption fine structure (XAFS) spectra of Ni/SiOCN samples derived from (a) Du1800-Ni and (b) PHPS-Ni precursors at different pyrolysis temperatures as well as reference materials $\left(\mathrm{Ni}, \mathrm{Ni}_{2} \mathrm{Si}\right.$, and $\left.\mathrm{NiO}\right)$. 

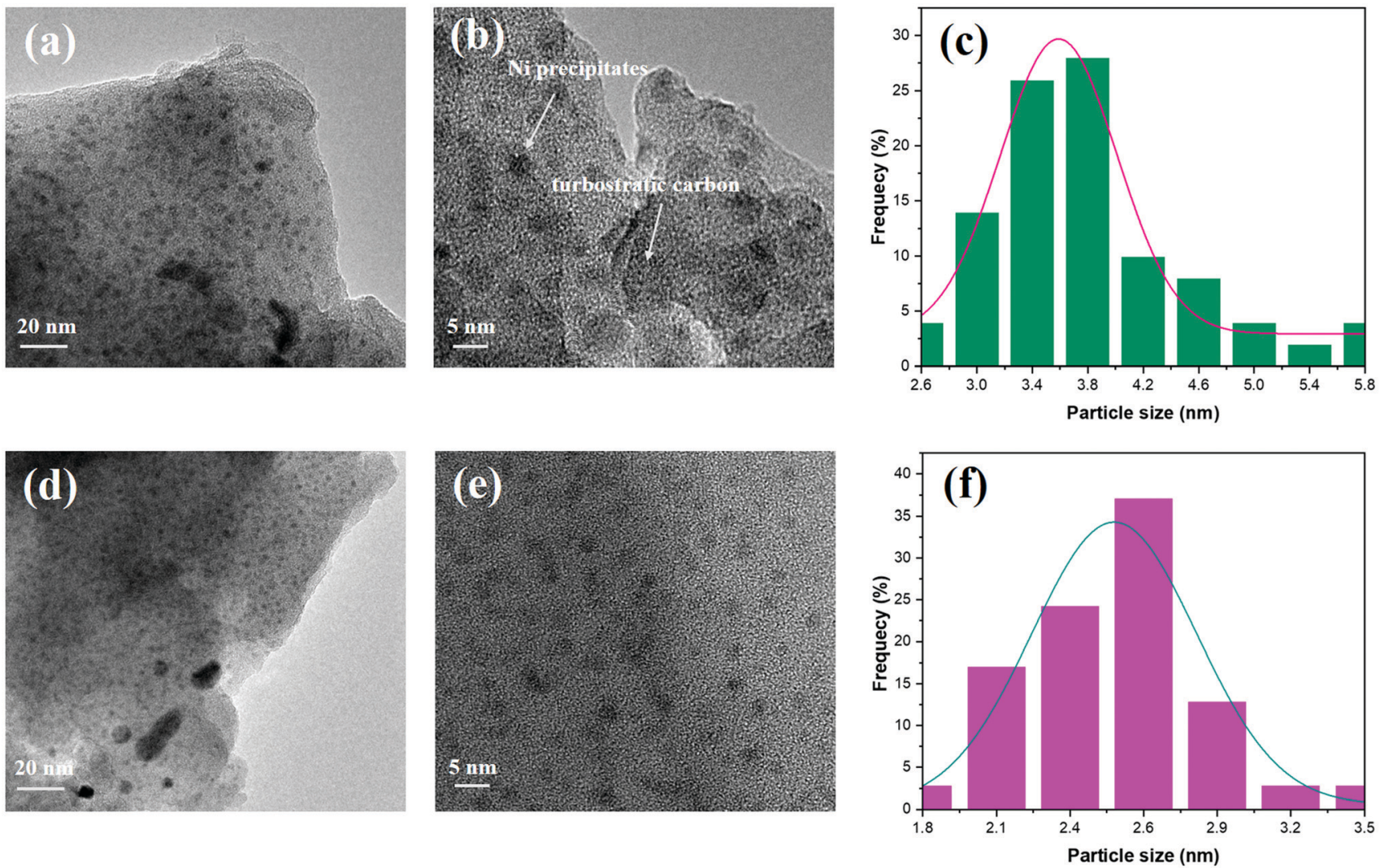

Fig. 10 TEM images of ( $a$ and b) 700Ar-Du1800-Ni and ( $\mathrm{d}$ and e) 700Ar-PHPS-Ni samples. Their particle size distribution is shown in (c) and (f), respectively.

observed. Typically, the free carbon phase in polymer-derived ceramics has not yet been found upon thermolysis between 700 and $900{ }^{\circ} \mathrm{C}$, and higher pyrolysis temperatures are usually required to initiate the formation and precipitation of turbostratic carbon. ${ }^{77-81}$ However, the presence of transition metal catalysts such as $\mathrm{Ni}$ and $\mathrm{Fe}$ in PDCs can greatly lower its formation temperature. ${ }^{43,82}$ In addition, no turbostratic carbon is observed in the 700Ar-PHPS-Ni sample, which can be explained by the carbon-free backbone chain of the PHPS polymer.

\section{Porosity and surface area of $\mathrm{Ni} / \mathrm{SiOCN}$ ceramic nanocomposites}

Fig. 11 shows nitrogen physisorption isotherms of Ni/SiOCN ceramic nanocomposites derived from Du1800-Ni and PHPS-Ni precursors at different pyrolysis temperatures. 700Ar-Du1800$\mathrm{Ni}$ and 900Ar-Du1800-Ni samples derived from the Du1800-Ni precursor exhibit type I isotherms corresponding to microporous materials, while the 1100Ar-Du1800-Ni sample shows a nonporous structure. Accordingly, 700Ar-Du1800-Ni and 900Ar-Du1800-Ni samples possess a BET specific surface area of $\sim 361$ and $\sim 232 \mathrm{~m}^{2} \mathrm{~g}^{-1}$, respectively, which are much higher than that of the 1100Ar-Du1800-Ni sample $\left(6.8 \mathrm{~m}^{2} \mathrm{~g}^{-1}\right)$. Interestingly, all Ni/SiOCN ceramic nanocomposites derived from PHPS-Ni precursor manifest nonporous structures with a low BET specific surface area of $\sim 9, \sim 7.5$, and $\sim 7 \mathrm{~m}^{2} \mathrm{~g}^{-1}$ for 700Ar-PHPS-Ni, 900Ar-PHPS-Ni, and 1100Ar-PHPS-Ni, respectively. The nucleation and growth of micropores in PDCs can be explained by the amount and type of gaseous species released during the polymer-to-ceramic transformation process such as $\mathrm{H}_{2}, \mathrm{CH}_{4}, \mathrm{NH}_{3}$, and other hydrocarbons. ${ }^{83}$ For instance, the PHPS polymer has no hydrocarbon units in its backbone chain (Fig. S3, ESI $\dagger$ ). Therefore, the thermolysis of the PHPS-Ni precursor results in the evolution of few gaseous species such as $\mathrm{H}_{2}$ and $\mathrm{NH}_{3}$ in addition to a small amount of gaseous $\mathrm{CH}_{4}$ from the decomposition of acetate groups. Consequently, all $\mathrm{Ni} / \mathrm{SiOCN}$ ceramic nanocomposites derived from the PHPS-Ni precursor show nonporous structures with a low surface area. In contrast, Durazane 1800 is a hydrocarbon-rich polymer, and its thermolysis results in the release of several gaseous hydrocarbons. Therefore, micropores are formed in 700Ar-Du1800-Ni and 900Ar-Du1800-Ni samples during the pyrolysis of the Du1800-Ni precursor at 700-900 ${ }^{\circ} \mathrm{C}$. However, the generated micropores are not stable and will collapse with increasing thermolysis temperature. Thus, the 1100Ar-Du1800-Ni sample exhibits a nonporous structure. Moreover, our previous work showed that the in situ formed metallic nickel nanoparticles could also play a role in the formation and stability of these micropores in the PDCs during thermolysis. ${ }^{44}$ As discussed above, nickel nanoparticles can catalyze the formation of hydrocarbon species and reduce the critical barrier for the formation of gaseous species during the polymer-to-ceramic transformation, which facilitates the heterogeneous nucleation of pores due to the release of small gas molecules such as $\mathrm{H}_{2}$, 

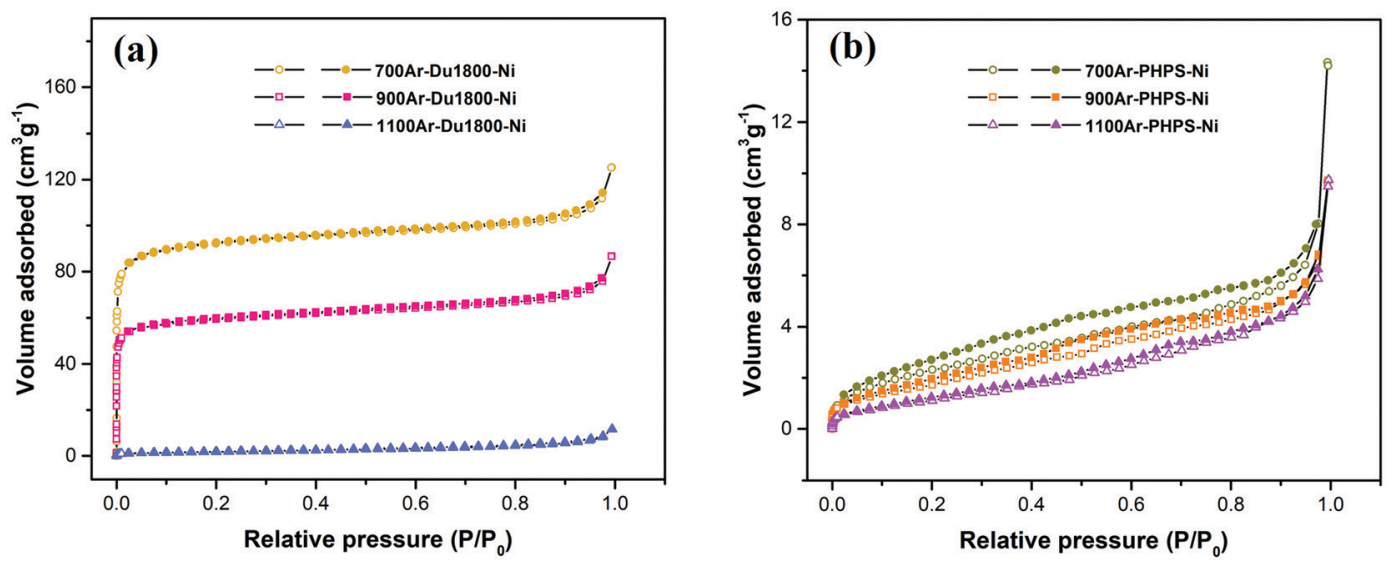

Fig. 11 Nitrogen physisorption isotherms of Ni/SiOCN ceramic nanocomposites derived from (a) Du1800-Ni and (b) PHPS-Ni precursors (open and filled symbols indicate the adsorption and desorption stage, respectively).

$\mathrm{CH}_{4}$, and $\mathrm{NH}_{3}$. In this way, micropores are prone to be formed instead of macropores and abnormal pore growth. In addition, higher cross-linking of the precursors through the formation of carbosilane units can enhance the pore stability during the pyrolysis. Moreover, nickel nanoparticles lower the formation temperature of turbostratic carbon by some hundred degrees. Accordingly, the formed nickel nanoparticles and turbostratic carbon with higher mechanical stability than that of the neighboring microporous matrix behave as nanofillers and reinforce the microporous structure, subsequently increasing the stability of micropores in the entire matrix of the sample.

\section{Catalytic properties of $\mathrm{Ni} / \mathrm{SiOCN}$ ceramic nanocomposites in} dry reforming of methane

Dry reforming of methane (DRM) with carbon dioxide is a promising process to convert the two main greenhouse gases into $\mathrm{CO} / \mathrm{H}_{2}$ mixtures with a ratio close to unity (eqn (1)). ${ }^{84}$ Typical deviation from the unity $\mathrm{H}_{2}$ : $\mathrm{CO}$ ratio and higher $\mathrm{CO}_{2}$ reaction rates compared to $\mathrm{CH}_{4}$ are due to the occurrence of the reverse water gas shift (RWGS) reaction (eqn (2)). The DRM process has been chosen as a representative catalytic system containing supported nickel nanoparticles that perform under harsh conditions.

$$
\begin{aligned}
& \mathrm{CO}_{2}(\text { gas })+\mathrm{CH}_{4}(\text { gas }) \rightarrow 2 \mathrm{CO}(\text { gas })+2 \mathrm{H}_{2}(\text { gas }) \\
& \Delta H_{298 \mathrm{~K}}^{\circ}=274 \mathrm{~kJ} \mathrm{~mol}^{-1} \\
& \mathrm{CO}_{2}(\text { gas })+\mathrm{H}_{2}(\text { gas }) \rightarrow \mathrm{CO}(\text { gas })+\mathrm{H}_{2} \mathrm{O}(\text { gas }) \\
& \Delta H_{298 \mathrm{~K}}^{\circ}=41 \mathrm{~kJ} \mathrm{~mol}^{-1}
\end{aligned}
$$

The deactivation of catalysts that are mainly caused by nickel particle sintering (the decrease of active surface area) and potentially via coke formation can contribute to the decrease of reaction rates at a given temperature. Surface carbon formation resulting from $\mathrm{CO}$ disproportionation or $\mathrm{CH}_{4}$ decomposition (eqn (3)-(5)) has been claimed to deactivate the catalyst or also to be involved in the reaction mechanism, ${ }^{53,85,86}$ although an excess carbon can plug the reactor. ${ }^{87}$ Another option can be the transformation of the active metal nickel nanoparticles to their silicide phases, ${ }^{88}$ which displays a diminished activity toward syngas formation. The occurrence of the different potential deactivation mechanisms will be later discussed using post-catalytic XRD, XPS, and TEM data.

$$
\begin{gathered}
2 \mathrm{CO}(\text { gas }) \rightarrow \mathrm{CO}_{2}(\text { gas })+\mathrm{C}_{\mathrm{s}} \quad \Delta H_{298 \mathrm{~K}}^{\circ}=-172 \mathrm{~kJ} \mathrm{~mol}^{-1} \\
\mathrm{CO}(\text { gas })+\mathrm{H}_{2}(\text { gas }) \rightarrow \mathrm{C}_{\mathrm{s}}+\mathrm{H}_{2} \mathrm{O}(\text { gas }) \\
\Delta H_{298 \mathrm{~K}}^{\circ}=-131 \mathrm{~kJ} \mathrm{~mol}^{-1} \\
\left.\left.\mathrm{CH}_{4} \text { (gas }\right)+2 \mathrm{H}_{2} \text { (gas }\right)+\mathrm{C}_{\mathrm{s}} \quad \Delta H_{298 \mathrm{~K}}^{\circ}=75 \mathrm{~kJ} \mathrm{~mol}^{-1}
\end{gathered}
$$

The catalytic properties of Ni/SiOCN ceramic nanocomposites derived from Du1800-Ni and PHPS-Ni precursors are studied in the DRM process in a plug-flow fixed bed-reactor at reactant ratios of $\mathrm{CH}_{4}: \mathrm{CO}_{2}: \mathrm{N}_{2}=1: 1: 3$ and GHSV $=120000 \mathrm{~N} \mathrm{~mL} \mathrm{~h}^{-1} \mathrm{~g}_{\text {cat }}{ }^{-1}$, as shown in Fig. 12. All samples show low or no activity towards DRM at $500{ }^{\circ} \mathrm{C}$, which is most possibly due to the low detection limit of the GC. At higher temperatures such as $600{ }^{\circ} \mathrm{C}, 700{ }^{\circ} \mathrm{C}$, and $800{ }^{\circ} \mathrm{C}$, all samples show activity for the DRM process. The reaction rates increase with temperature due to the endothermic nature of the DRM reaction. For all catalytic tests, the reaction rate of $\mathrm{CO}_{2}$ is always higher than that of $\mathrm{CH}_{4}$. This can be attributed to the occurrence of the reverse water gas shift (RWGS) reaction (eqn (2)), which further reacts to $\mathrm{CO}_{2}$ and produces the observed deviation from the unity of the $\mathrm{H}_{2}$ : CO ratio. However, the $\mathrm{CO}_{2}$ reaction rate is a little lower than that of $\mathrm{CH}_{4}$ for catalyst 900Ar-PHPS-Ni, which is caused by more injection of $\mathrm{CO}_{2}$ than expected into the reactor. For the samples derived from the Du1800-Ni precursor, all show very close reaction rates when measured at 500 and $600{ }^{\circ} \mathrm{C}$. However, with increasing test temperature, catalyst 900ArDu1800-Ni shows much better performance, and the $\mathrm{CH}_{4}$ reaction rate at 700 and $800{ }^{\circ} \mathrm{C}$ is around 0.08 and $0.16 \mathrm{~mol} \mathrm{~min}^{-1} \mathrm{~g}_{\mathrm{Ni}}{ }^{-1}$, respectively (Fig. 12a). Moreover, all the Du1800-Ni precursor derived samples display remarkable stability at all temperatures tested, suggesting a soft deactivation effect. All catalysts derived from the PHPS-Ni precursor show very low reaction rates at $500{ }^{\circ} \mathrm{C}$ and $600{ }^{\circ} \mathrm{C}$ (Fig. 12b). The reaction rate is greatly increased when the test is conducted at $700{ }^{\circ} \mathrm{C}$ except for catalyst 1100Ar-PHPS-Ni, 

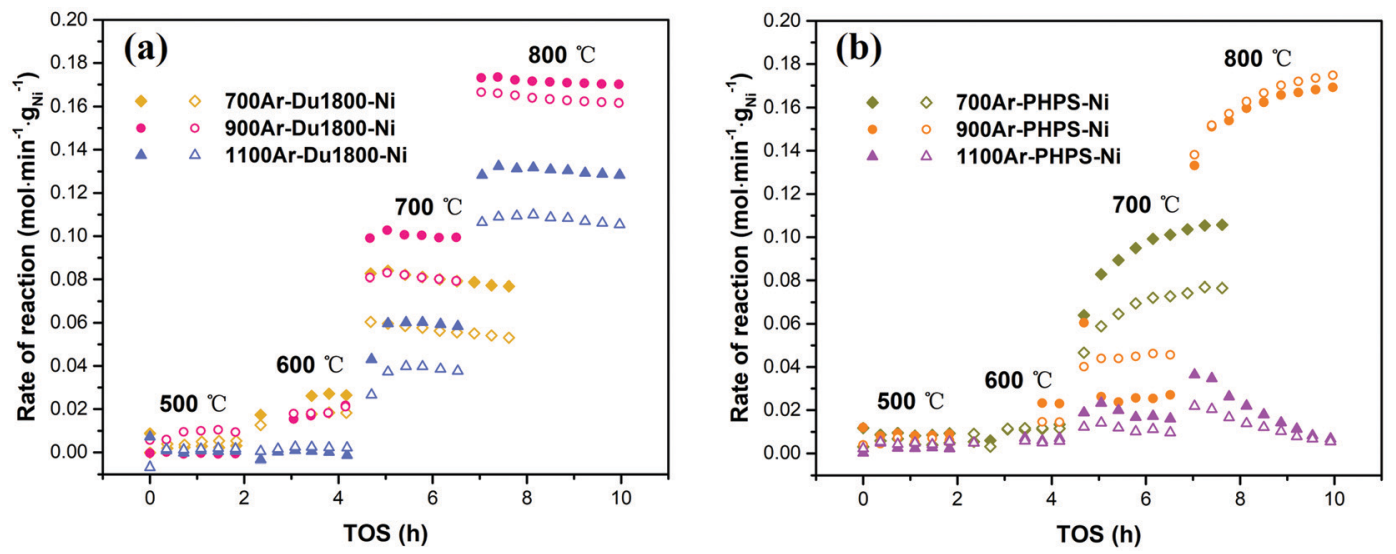

Fig. $12 \mathrm{CO}_{2}$ and $\mathrm{CH}_{4}$ reaction rates for the tests at $500{ }^{\circ} \mathrm{C}, 600{ }^{\circ} \mathrm{C}, 700{ }^{\circ} \mathrm{C}$, and $800{ }^{\circ} \mathrm{C}$, using a plug-flow fixed-bed reactor at reactant ratios of $\mathrm{CH}_{4}: \mathrm{CO}_{2}: \mathrm{N}_{2}=1: 1: 3$ and GHSV $=120000 \mathrm{~N} \mathrm{~mL} \mathrm{~h}^{-1} \mathrm{~g}_{\mathrm{cat}}{ }^{-1}$ (open and filled symbols represent $\mathrm{CH}_{4}$ and $\mathrm{CO}_{2}$ reaction rate, respectively).

which displays a moderate increase in terms of the reaction rate and a strong deactivation effect. In contrast, the catalysts pyrolyzed at 700 and $900{ }^{\circ} \mathrm{C}$ show an increase in the reaction rate at higher testing temperatures. This activation phenomenon might be explained by changes in the crystallite/particle size, a phase transition, and/or the removal of turbostratic carbon caused by oxidation with $\mathrm{CO}_{2}$ or $\mathrm{H}_{2} \mathrm{O}$. Surface carbon oxidation can also occur via eqn (4). Although $\mathrm{H}_{2} \mathrm{O}$ is not introduced as a reactant, it can be produced by the RWGS and oxidize carbon to produce $\mathrm{CO}$ and $\mathrm{H}_{2}$. Our HRTEM investigations on PHPS-Ni catalysts showed that the metallic Ni nanoparticles are embedded in carbon onions, which might reduce their catalytic activity. Removal of carbon can clean the catalyst surface, exposing more nickel to reaction and thereby increasing reaction rates. ${ }^{53}$ The 900Ar-PHPS-Ni catalyst exhibits the best performance among all samples with the highest $\mathrm{CH}_{4}$ reaction rate of $0.18 \mathrm{~mol} \mathrm{~min}^{-1} \mathrm{~g}_{\mathrm{Ni}}{ }^{-1}$ at $800{ }^{\circ} \mathrm{C}$. The reason for the differences in the performance of these samples can be explained by differences in the catalyst configuration, which includes the surface area (Fig. 11), initial nickel nanoparticle size (Fig. 10), and chemical compositions (Fig. 9 and Fig. S6, ESI $\dagger$ ).

The catalytic performance (reaction rate of $\mathrm{CH}_{4}$ ) in our work is summarized in Table S4 (ESI $\dagger$ ). As compared with other studies (Table S5, ESI $\dagger$ ), ${ }^{47-52}$ our prepared Ni/SiOCN catalysts show remarkable catalytic activity towards the DRM process even though the catalyst configuration was not optimized for this particular reaction. This demonstrates that the in situ formation of nickel nanoparticles in the PDC matrix is a promising approach to prepare heterogeneous catalysts for the DRM process. Catalyst design and optimization can further improve the performance of this type of catalyst for the DRM and other catalytic processes that occur on supported nickel nanoparticles.

To understand the catalytic performance, post-catalytic characterization is required on the spent catalysts. However, the spent catalysts recovered from the plug-flow fixed-bed reactor after the catalytic tests contain quartz powder to dilute the catalysts and ensure homogeneous temperature and pressure across the catalytic bed. These impurities in the spent catalysts might add difficulties during the preparation of the samples for post characterization as well as the interpretation of the results of characterization. Therefore, the catalytic tests were repeated without using any powder for dilution in a recirculating batch reactor initially containing a $\mathrm{CH}_{4}: \mathrm{CO}_{2}: \mathrm{Ar}=$ $1: 1: 8$ mixture at 1000 mbar of pressure, as detailed in the ESI. $\dagger$ All samples showed activity towards the DRM and the production of syngas as demonstrated by the conversion of $\mathrm{CO}_{2}$ and the detection of $\mathrm{CO}$ and $\mathrm{H}_{2}$ in the MS spectra (Fig. S10, ESI $\dagger$ ), therefore allowing the use of the spent catalysts for further characterization. The high-resolution XRD patterns of the catalysts before and after DRM tests are shown in Fig. 13. For each given catalyst, the patterns of PHPS-Ni catalysts before and after DRM generally reveal no noteworthy phase transitions during catalysis. In contrast, a new set of XRD reflections corresponding to the NiSi phase are observed in the patterns of 900Ar-Du1800-Ni and 1100Ar-Du1800-Ni catalysts after the DRM test. Moreover, the full width at half maximum (FWHM) of the Ni(111) reflection belonging to each sample is slightly decreased after the DRM test, suggesting the slight increase in the crystallite size of metallic nickel in the catalysts. The increase in the crystallite size of metallic Ni (i.e., crystallinity) in the 900Ar-Du1800-Ni catalyst under different DRM conditions is also confirmed by in situ synchrotron XRD experiments (Fig. S11, ESI $\dagger$ ). As shown in Fig. S11a (ESI $\dagger$ ), the XRD reflections corresponding to the metallic Ni phase become more intense and sharp with time during the pre-reduction step in a $\mathrm{H}_{2}$ atmosphere at $600{ }^{\circ} \mathrm{C}$ as well as under DRM reactions at 600 and $800{ }^{\circ} \mathrm{C}$. In contrast, no remarkable structural changes are observed for the 1100Ar-PHPS-Ni sample during the prereduction step and DRM reactions (see Fig. S11b, ESI $\dagger$ ), which agrees with the ex situ XRD results. This might be due to the low activity of this sample towards DRM (see Fig. 12b). The formation of nickel silicide and the sintering of nickel particles can result, to some degree, in catalyst deactivation. ${ }^{53,88}$ This deactivation is soft for the time on stream tested as proved by the catalytic tests previously. Surface carbon formation resulting from CO disproportionation or $\mathrm{CH}_{4}$ decomposition (eqn (3)-(5)) can be 

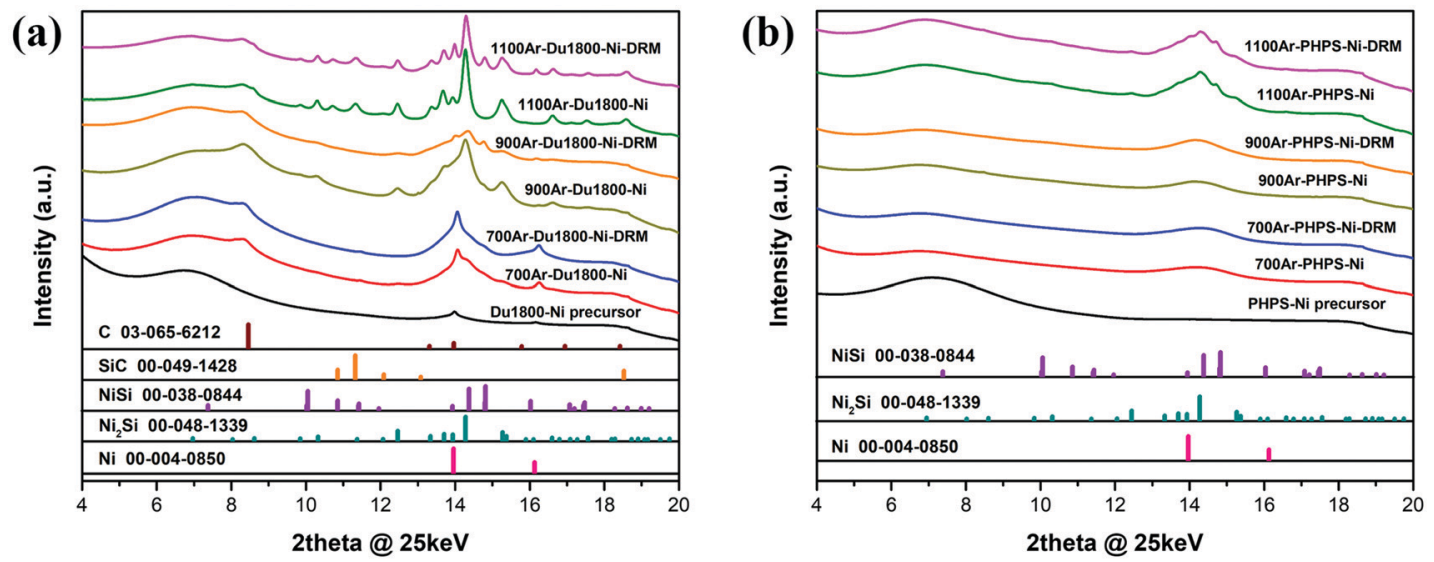

Fig. 13 Room-temperature high-resolution XRD patterns of (a) Du1800-Ni and (b) PHPS-Ni precursors and their derived ceramic nanocomposites after pyrolysis at $700^{\circ} \mathrm{C}, 900^{\circ} \mathrm{C}$, and $1100^{\circ} \mathrm{C}$ before and after DRM. Reference material patterns are Ni (ICDD-PDF-00-004-0850), Ni 2 Si (ICDD-PDF-00-0481339), NiSi (ICDD-PDF-00-038-0844), SiC (ICDD-PDF-00-049-1428) and C (ICDD-PDF-03-065-6212).

another reason for the deactivation of the catalyst. ${ }^{53,85,86}$ However, the formation of surface carbon cannot be confirmed from XRD results because all Du1800-Ni group samples contain graphitic carbon before interaction with the DRM reactants. Similarly, the PHPS-Ni group samples display no graphitic reflections before or after DRM, suggesting that (if formed) surface carbon resulting from eqn (3)-(5) is amorphous or below the technique's detection limit.

The Ni 2p X-ray photoelectron spectra of all samples before and after the DRM test are shown in Fig. S12 (ESI $\dagger$ ). The peaks at $855.8 \mathrm{eV}$ and $873.4 \mathrm{eV}$ that are associated with $\mathrm{Ni}^{2+}$ disappeared after the DRM test, which suggests the reduction of the NiO phase in the samples to metallic Ni or nickel silicide under DRM conditions. This change is logical if we consider the reductive nature of the effluent gas composition after DRM. As shown in Fig. S13 (ESI $\dagger$ ), the C 1s X-ray photoelectron spectra of all samples before and after DRM can be fitted with four peaks at 284.1, 284.8, 286.3, and $288.6 \mathrm{eV}$, which can be assigned to $\mathrm{C}-\mathrm{Si}, \mathrm{C}-\mathrm{C}, \mathrm{C}-\mathrm{N}$, and $\mathrm{C}-\mathrm{O}$ bonds, respectively. ${ }^{89}$ For $\mathrm{Ni} / \mathrm{SiOCN}$ samples derived from the Du1800-Ni precursor, the main peak in the spectra is due to $\mathrm{C}-\mathrm{C}$ bonds in graphite or amorphous carbon, while the main peak in the spectra of PHPS-Ni samples is assigned to C-Si bonds. Moreover, the analysis of the spectrum survey (Tables S2 and S3, ESI $\dagger$ ) reveals that the amount of carbon on the surface of Du1800-Ni samples is much higher than that on the surface of PHPS-Ni samples and increases after DRM. This result points out the formation of surface carbon from eqn (3)-(5). For the PHPS-Ni samples (except for the sample pyrolyzed at $700{ }^{\circ} \mathrm{C}$ ), the carbon content on the surface of the catalysts after DRM slightly increases. These results complement XRD analysis and suggest that the carbon content on the surface of catalysts increases after DRM. No remarkable increase in the amount of graphitic carbon can be observed by XRD, suggesting that the formed carbon might be amorphous or in a low amount.

Fig. 14 shows the TEM characterization performed on the catalysts after DRM-atmosphere exposure. Several multiwalled $\mathrm{sp}^{2}$-carbon nanotubes are formed on the surface of the spent 900Ar-Du1800-Ni catalyst, produced from $\mathrm{CH}_{4}$ decomposition or CO disproportionation. In contrast, a small number of carbon nanotubes are formed on the surface of the spent 1100Ar-PHPS-Ni catalyst. The presence of surface carbon is not necessarily linked to catalyst deactivation, as under specific conditions surface carbon can act as an intermediate toward the generation of syngas by oxidation with $\mathrm{CO}_{2} \cdot{ }^{53}$ Therefore, the presence of nanotubes on the 900Ar-Du1800-Ni samples does not necessarily point to higher deactivation but can be a result of an increased $\mathrm{CH}_{4}$ cracking activity, which produces the necessary intermediate for the reaction with $\mathrm{CO}_{2}$. This fact has been supported by an increased reaction rate for this type of catalyst, as shown in Fig. 12a. TEM characterization further complements XRD and XPS data and highlights that carbon formation is a surface phenomenon mainly occurring on the
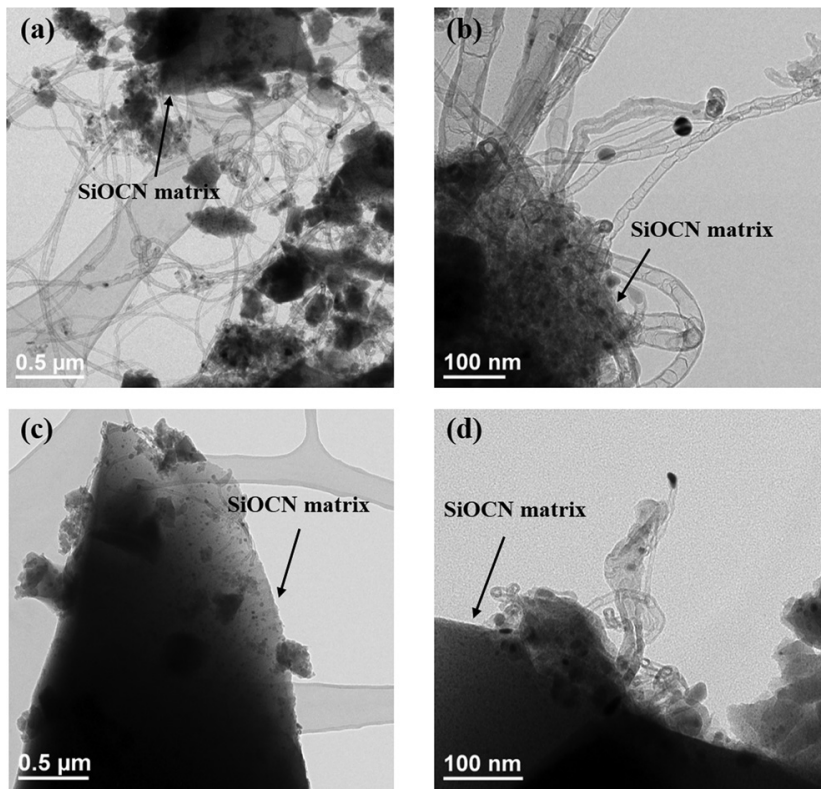

Fig. 14 TEM images of the ( $a$ and b) 900Ar-Du1800-Ni and (c and d) 1100 Ar-PHPS-Ni catalysts after the DRM test in a recirculating batch reactor. 
surface of Du1800-Ni samples. The relatively small amount of graphitic carbon results in no observable bulk changes for the Du1800-Ni samples but a significant increase of the surface carbon concentration, as proved by XPS. For these catalysts, the formation of carbon nanotubes does not lead to catalyst deactivation as verified by remarkably stable reaction rates of the Du1800samples for the duration of the catalytic tests. All synthesized samples have proved their activity for $\mathrm{CH}_{4}$ and $\mathrm{CO}_{2}$ conversion to produce syngas, and we anticipate their applicability to other catalytic reactions performed on supported nickel nanoparticles.

\section{Conclusions}

Ni-Containing polysilazane Du1800-Ni and PHPS-Ni precursors have been synthesized through the chemical reaction of $\mathrm{Ni}(\mathrm{Ac})_{2} \cdot 4 \mathrm{H}_{2} \mathrm{O}$ with poly(vinyl)silazane (Durazane 1800) and perhydropolysilazane NN120-20 (A) (PHPS), respectively. Nickel nanoparticles are in situ formed during the reaction between $\mathrm{Ni}(\mathrm{Ac})_{2} \cdot 4 \mathrm{H}_{2} \mathrm{O}$ and $-\mathrm{Si}-\mathrm{H}$ groups of the polymers. The formed $\mathrm{Ni}$ nanoparticles in Ni-containing precursors are stable after pyrolyzing at $700{ }^{\circ} \mathrm{C}$ under an argon atmosphere, but they react with the SiOCN matrix at higher pyrolysis temperatures $\left(\geq 900{ }^{\circ} \mathrm{C}\right.$ ) to form the nickel silicide $\left(\mathrm{Ni}_{2} \mathrm{Si}\right)$ phase. The ceramic nanocomposites derived from the Du1800-Ni precursor by pyrolyzing at 700 and $900{ }^{\circ} \mathrm{C}$ show a high BET specific surface area of $\sim 361$ and $\sim 232 \mathrm{~m}^{2} \mathrm{~g}^{-1}$, respectively, while all the pyrolyzed samples derived from the PHPS-Ni precursor exhibit a nonporous structure. Catalytic tests for the dry reforming of methane process reveals that all samples are active towards syngas formation, but the samples pyrolyzed at $900{ }^{\circ} \mathrm{C}$ show the best performance. Demonstrated by its applicability to the dry reforming of methane reaction, in situ formation of nickel nanoparticles in PDCs shows great potential as a preparation method for heterogeneous catalysts.

\section{Author contributions}

J. Wang synthesized the materials, carried out ATR-FTIR characterization, analyzed and discussed the experimental data, prepared and drew the images and graphics for the publication and wrote the manuscript. A. Gili and R. Schomäcker assisted in the catalytic tests in a plug-flow fixed-bed reactor; A. Gili conducted the collection of the synchrotron XRD patterns. M. Grünbacher and S. Penner carried out the catalytic tests in the recirculating batch reactor. S. Praetz and C. Schlesiger were involved in the XAFS characterization and result analysis. J. D. Epping supported the solid NMR characterization. O. Görke helped with Raman and EDX characterization. G. Schuck carried out the XANES characterization. A. Gurlo and M. F. Bekheet supervised this research project, and contributed to the experimental design and data interpretation.

\section{Conflicts of interest}

The authors declare no conflicts of interest.

\section{Acknowledgements}

We would like to thank Harald Link for collecting ICP-OES data, Heinz Sap for TG-MS, Maria Unterweger for XPS, and Christina Eichenauer for nitrogen sorption. We thank Sören Selve and Jan Ron Justin Simke for performing TEM characterization. Jun Wang acknowledges the financial support from the China Scholarship Council (201604910900) and DAAD STIBETgrant for degree completion awarded by Technische Universität Berlin. This research used resources of the Advanced Light Source, which is a DOE Office of Science User Facility under contract no. DE-AC02-05CH11231. Albert Gili thanks the Unifying Systems in Catalysis (UniSysCat), which is funded by the Deutsche Forschungsgemeinschaft (DFG, German Research Foundation) under Germany's Excellence Strategy - EXC 2008/1-390540038.

\section{References}

1 V. Pareek, A. Bhargava, R. Gupta, N. Jain and J. Panwar, Adv. Sci., Eng. Med., 2017, 9, 527-544.

2 M. J. Ndolomingo, N. Bingwa and R. Meijboom, J. Mater. Sci., 2020, 55, 6195-6241.

3 A. J. Shnoudeh, I. Hamad, R. W. Abdo, L. Qadumii, A. Y. Jaber, H. S. Surchi and S. Z. Alkelany, in Biomaterials and Bionanotechnology, ed. R. K. Tekade, Academic Press, 2019, pp. 527-612.

$4 \mathrm{H}$. H. El-Maghrabi, A. A. Nada, S. Roualdes and M. F. Bekheet, Int. J. Hydrogen Energy, 2020, 45, 32000-32011.

5 H. H. El-Maghrabi, A. A. Nada, M. F. Bekheet, S. Roualdes, W. Riedel, I. Iatsunskyi, E. Coy, A. Gurlo and M. Bechelany, J. Colloid Interface Sci., 2020, 587, 457-466.

6 R. N. Baig and R. S. Varma, ACS Sustainable Chem. Eng., 2013, 1, 805-809.

7 J. H. Kang, L. D. Menard, R. G. Nuzzo and A. I. Frenkel, J. Am. Chem. Soc., 2006, 128, 12068-12069.

8 H. S. Whang, M. S. Choi, J. Lim, C. Kim, I. Heo, T.-S. Chang and H. Lee, Catal. Today, 2017, 293, 122-128.

9 Z. Jin, M. Xiao, Z. Bao, P. Wang and J. Wang, Angew. Chem., Int. Ed., 2012, 51, 6406-6410.

10 M. F. Bekheet, M. Grünbacher, L. Schlicker, A. Gili, A. Doran, J. D. Epping, A. Gurlo, B. Klötzer and S. Penner, CrystEngComm, 2019, 21, 145-154.

11 M. F. Bekheet, P. Delir Kheyrollahi Nezhad, N. Bonmassar, L. Schlicker, A. Gili, S. Praetz, A. Gurlo, A. Doran, Y. Gao, M. Heggen, A. Niaei, A. Farzi, S. Schwarz, J. Bernardi, B. Klötzer and S. Penner, ACS Catal., 2021, 11, 43-59.

12 N. Bonmassar, M. F. Bekheet, L. Schlicker, A. Gili, A. Gurlo, A. Doran, Y. Gao, M. Heggen, J. Bernardi, B. Klötzer and S. Penner, ACS Catal., 2020, 10, 1102-1112.

13 A. Gili, L. Schlicker, M. F. Bekheet, O. Görke, D. Kober, U. Simon, P. Littlewood, R. Schomäcker, A. Doran, D. Gaissmaier, T. Jacob, S. Selve and A. Gurlo, ACS Catal., 2019, 9, 6999-7011.

14 L. Schlicker, M. F. Bekheet, A. Gili, A. Doran, A. Gurlo, K. Ploner, T. Schachinger and S. Penner, J. Solid State Chem., 2018, 266, 93-99. 
15 R. Riedel, A. Kienzle, W. Dressler, L. Ruwisch, J. Bill and F. Aldinger, Nature, 1996, 382, 796-798.

16 A. Müller, J. Peng, H. J. Seifert, J. Bill and F. Aldinger, Chem. Mater., 2002, 14, 3406-3412.

17 S. Fu, M. Zhu and Y. Zhu, J. Adv. Ceram., 2019, 8, 457-478.

18 A. Lale, M. Schmidt, M. D. Mallmann, A. V. A. Bezerra, E. D. Acosta, R. A. F. Machado, U. B. Demirci and S. Bernard, Surf. Coat. Technol., 2018, 350, 569-586.

19 S. Schwarz, M. Friedrich, G. Motz and R. Kempe, Z. Anorg. Allg. Chem., 2015, 641, 2266-2271.

20 D. Schumacher, M. Wilhelm and K. Rezwan, J. Am. Ceram. Soc., 2020, 103, 2991-3001.

21 M. Schubert, M. Wilhelm, S. Bragulla, C. Sun, S. Neumann, T. M. Gesing, P. Pfeifer, K. Rezwan and M. Bäumer, Catal. Lett., 2017, 147, 472-482.

22 H. P. Macedo, R. L. Medeiros, J. Ilsemann, D. M. Melo, K. Rezwan and M. Wilhelm, Microporous Mesoporous Mater., 2019, 278, 156-166.

23 M. Adam, S. Kocanis, T. Fey, M. Wilhelm and G. Grathwohl, J. Eur. Ceram. Soc., 2014, 34, 1715-1725.

24 M. Wilhelm, M. Adam, M. Baeumer and G. Grathwohl, Adv. Eng. Mater., 2008, 10, 241-245.

25 G. Glatz, T. Schmalz, T. Kraus, F. Haarmann, G. Motz and R. Kempe, Chem. - Eur. J., 2010, 16, 4231-4238.

26 D. Forberg, T. Schwob, M. Zaheer, M. Friedrich, N. Miyajima and R. Kempe, Nat. Commun., 2016, 7, 1-6.

27 D. Forberg, T. Schwob and R. Kempe, Nat. Commun., 2018, 9, 1-7.

28 D. Forberg, J. Obenauf, M. Friedrich, S.-M. Hühne, W. Mader, G. Motz and R. Kempe, Catal. Sci. Technol., 2014, 4, 4188-4192.

29 M. Birot, J.-P. Pillot and J. Dunogues, Chem. Rev., 1995, 95, 1443-1477.

30 P. Colombo, G. Mera, R. Riedel and G. D. Soraru, J. Am. Ceram. Soc., 2010, 93, 1805-1837.

31 P. Greil, Adv. Eng. Mater., 2000, 2, 339-348.

32 P. Greil, J. Am. Ceram. Soc., 1995, 78, 835-848.

33 A. Francis, E. Ionescu, C. Fasel and R. Riedel, Inorg. Chem., 2009, 48, 10078-10083.

34 M. Hojamberdiev, R. M. Prasad, K. Morita, M. A. Schiavon and R. Riedel, Microporous Mesoporous Mater., 2012, 151, 330-338.

35 Y. Wang, Y. Feng, X. Guo, Y. Liu and H. Gong, RSC Adv., 2017, 7, 46215-46220.

36 K. Kulbaba, A. Cheng, A. Bartole, S. Greenberg, R. Resendes, N. Coombs, A. Safa-Sefat, J. E. Greedan, H. D. Stöver and G. A. Ozin, J. Am. Chem. Soc., 2002, 124, 12522-12534.

37 X. Chen, Z. Su, L. Zhang, M. Tang, Y. Yu, L. Zhang and L. Chen, J. Am. Ceram. Soc., 2010, 93, 89-95.

38 E. Ionescu, C. Linck, C. Fasel, M. Müller, H. J. Kleebe and R. Riedel, J. Am. Ceram. Soc., 2010, 93, 241-250.

39 T. Ishikawa, S. Kajii, K. Matsunaga, T. Hogami, Y. Kohtoku and T. Nagasawa, Science, 1998, 282, 1295-1297.

40 P. Amoros, D. Beltran, C. Guillem and J. Latorre, Chem. Mater., 2002, 14, 1585-1590.

41 G. Hahn, J. K. Ewert, C. Denner, D. Tilgner and R. Kempe, ChemCatChem, 2016, 8, 2461-2465.
42 S. M. Sachau, M. Zaheer, A. Lale, M. Friedrich, C. E. Denner, U. B. Demirci, S. Bernard, G. Motz and R. Kempe, Chem. Eur. J., 2016, 22, 15508-15512.

43 T. Schmalz, T. Kraus, M. Günthner, C. Liebscher, U. Glatzel, R. Kempe and G. Motz, Carbon, 2011, 49, 3065-3072.

44 M. Seifollahi Bazarjani, H.-J. Kleebe, M. M. Müller, C. Fasel, M. Baghaie Yazdi, A. Gurlo and R. Riedel, Chem. Mater., 2011, 23, 4112-4123.

45 M. Seifollahi Bazarjani, M. M. Müller, H.-J. Kleebe, Y. Jüttke, I. Voigt, M. Baghaie Yazdi, L. Alff, R. Riedel and A. Gurlo, ACS Appl. Mater. Interfaces, 2014, 6, 12270-12278.

46 J. Wang, V. Schölch, O. Görke, G. Schuck, X. Wang, G. Shao, S. Schorr, M. F. Bekheet and A. Gurlo, Open Ceram., 2020, 1, 100001.

47 X. Li, D. Li, H. Tian, L. Zeng, Z.-J. Zhao and J. Gong, Appl. Catal., B, 2017, 202, 683-694.

48 Z. Li, L. Mo, Y. Kathiraser and S. Kawi, ACS Catal., 2014, 4, 1526-1536.

49 T. Xie, L. Shi, J. Zhang and D. Zhang, Chem. Commun., 2014, 50, 7250-7253.

50 J. Zhang and F. Li, Appl. Catal., B, 2015, 176-177, 513-521. 51 I. Luisetto, S. Tuti and E. Di Bartolomeo, Int. J. Hydrogen Energy, 2012, 37, 15992-15999.

52 K. Mette, S. Kühl, H. Düdder, K. Kähler, A. Tarasov, M. Muhler and M. Behrens, ChemCatChem, 2014, 6, 100-104.

53 A. Gili, L. Schlicker, M. F. Bekheet, O. Görke, S. Penner, M. Grünbacher, T. Götsch, P. Littlewood, T. J. Marks and P. C. Stair, ACS Catal., 2018, 8, 8739-8750.

54 A. Doran, L. Schlicker, C. Beavers, S. Bhat, M. Bekheet and A. Gurlo, Rev. Sci. Instrum., 2017, 88, 013903.

55 L. Schlicker, A. Doran, P. Schneppmüller, A. Gili, M. Czasny, S. Penner and A. Gurlo, Rev. Sci. Instrum., 2018, 89, 033904. 56 D. M. Többens and S. Zander, J. Large-Scale Res. Facil., 2016, 2, 49. 57 C. Schlesiger, L. Anklamm, H. Stiel, W. Malzer and B. Kanngießer, J. Anal. At. Spectrom., 2015, 30, 1080-1085.

58 B. Ravel and M. Newville, J. Synchrotron Radiat., 2005, 12, 537-541.

59 J. Yuan, S. Hapis, H. Breitzke, Y. Xu, C. Fasel, H.-J. Kleebe, G. Buntkowsky, R. Riedel and E. Ionescu, Inorg. Chem., 2014, 53, 10443-10455.

60 Y. D. Blum, D. B. MacQueen and H.-J. Kleebe, J. Eur. Ceram. Soc., 2005, 25, 143-149.

61 G. D. Soraru, F. Dalcanale, R. Campostrini, A. Gaston, Y. Blum, S. Carturan and P. R. Aravind, J. Mater. Chem., 2012, 22, 7676-7680.

62 J. Bill, J. Seitz, G. Thurn, J. Dürr, J. Canel, B. Janos, A. Jalowiecki, D. Sauter, S. Schempp and H. Lamparter, Phys. Status Solidi A, 1998, 166, 269-296.

63 Y. L. Li, E. Kroke, R. Riedel, C. Fasel, C. Gervais and F. Babonneau, Appl. Organomet. Chem., 2001, 15, 820-832.

64 J. Seitz, J. Bill, N. Egger and F. Aldinger, J. Eur. Ceram. Soc., 1996, 16, 885-891.

65 M. Weinmann, T. W. Kamphowe, J. Schuhmacher, K. Müller and F. Aldinger, Chem. Mater., 2000, 12, 2112-2122.

66 S. Traßl, D. Suttor, G. Motz, E. Rössler and G. Ziegler, J. Eur. Ceram. Soc., 2000, 20, 215-225. 
67 M. Zaheer, C. D. Keenan, J. Hermannsdörfer, E. Roessler, G. n. Motz, J. r. Senker and R. Kempe, Chem. Mater., 2012, 24, 3952-3963.

68 J. C. De Jesus, I. González, A. Quevedo and T. Puerta, J. Mol. Catal. A: Chem., 2005, 228, 283-291.

69 J. Zhang, J. Tu, X. Xia, Y. Qiao and Y. Lu, Sol. Energy Mater. Sol. Cells, 2009, 93, 1840-1845.

70 Y. Cao, L. Nyborg and U. Jelvestam, Surf. Interface Anal., 2009, 41, 471-483.

71 M. F. Bekheet, L. Dubrovinsky and A. Gurlo, J. Solid State Chem., 2015, 230, 301-308.

72 M. F. Bekheet, L. Schlicker, A. Doran, K. Siemensmeyer and A. Gurlo, Dalton Trans., 2018, 47, 2727-2738.

73 S. Steffen, M. Bauer, D. Decker and F. Richter, J. Appl. Polym. Sci., 2014, 131, 40375.

74 M. Sokri, M. Nazri, Y. Daiko, Z. Mouline, S. Honda and Y. Iwamoto, Inorganics, 2016, 4, 5.

75 N. Soltani, U. Simon, A. Bahrami, X. Wang, S. Selve, J. D. Epping, M. I. Pech-Canul, M. F. Bekheet and A. Gurlo, J. Eur. Ceram. Soc., 2017, 37, 4809-4820.

76 G. Mera, A. Navrotsky, S. Sen, H.-J. Kleebe and R. Riedel, J. Mater. Chem. A, 2013, 1, 3826-3836.
77 H. J. Kleebe, C. Turquat and G. D. Sorarù, J. Am. Ceram. Soc., 2001, 84, 1073-1080.

78 G. Mera, R. Riedel, F. Poli and K. Müller, J. Eur. Ceram. Soc., 2009, 29, 2873-2883.

79 H. J. Kleebe, Phys. Status Solidi A, 1998, 166, 297-313.

80 C. Turquat, H. J. Kleebe, G. Gregori, S. Walter and G. D. Sorarù, J. Am. Ceram. Soc., 2001, 84, 2189-2196.

81 G. Ziegler, H.-J. Kleebe, G. Motz, H. Müller, S. Traßl and W. Weibelzahl, Mater. Chem. Phys., 1999, 61, 55-63.

82 M. Scheffler, P. Greil, A. Berger, E. Pippel and J. Woltersdorf, Mater. Chem. Phys., 2004, 84, 131-139.

83 C. Schitco, M. S. Bazarjani, R. Riedel and A. Gurlo, J. Mater. Chem. A, 2015, 3, 805-818.

84 M. Bradford and M. Vannice, Catal. Rev., 1999, 41, 1-42.

85 J. Wei and E. Iglesia, J. Catal., 2004, 225, 116-127.

$86 \mathrm{~J}$. Wei and E. Iglesia, J. Catal., 2004, 224, 370-383.

87 P. Djinović, I. G. O. Črnivec, B. Erjavec and A. Pintar, Appl. Catal., B, 2012, 125, 259-270.

88 C. Hoffmann, P. Plate, A. Steinbrück and S. Kaskel, Catal. Sci. Technol., 2015, 5, 4174-4183.

89 N. B. Laidani and G. D. Sorarù, J. Mater. Res., 2015, 30, $770-781$. 